OPEN ACCESS

Edited by:

Rossen Donev,

MicroPharm Ltd., United Kingdom

Reviewed by:

Hongwen Song,

University of Science and Technology

of China, China

Peter Vitaliano,

University of Washington,

United States

*Correspondence:

Nicole Letourneau

nicole.letourneau@ucalgary.ca

Specialty section:

This article was submitted to

Neurogenomics,

a section of the journal

Frontiers in Neuroscience

Received: 06 May 2021 Accepted: 05 July 2021

Published: 27 July 2021

Citation:

Potter-Dickey A, Letourneau N, Silveira PP, Ntanda H, Giesbrecht GF Hart M, Dewell S and de Koning APJ (2021) Associations Among Parental

Caregiving Quality, Cannabinoid

Receptor 1 Expression-Based Polygenic Scores, and Infant-Parent Attachment: Evidence for Differential

Genetic Susceptibility?

Front. Neurosci. 15:704392. doi: 10.3389/fnins.2021.704392

\section{Associations Among Parental Caregiving Quality, Cannabinoid Receptor 1 Expression-Based Polygenic Scores, and Infant-Parent Attachment: Evidence for Differential Genetic Susceptibility?}

\author{
Amelia Potter-Dickey ${ }^{1}$, Nicole Letourneau ${ }^{1,2,3,4 *}$, Patricia P. Silveira ${ }^{5,6}$, Henry Ntanda ${ }^{2}$, \\ Gerald F. Giesbrecht ${ }^{2,3}$, Martha Hart ${ }^{2}$, Sarah Dewell ${ }^{1,7}$ and A. P. Jason de Koning ${ }^{8,9}$ \\ ${ }^{1}$ Faculty of Nursing, University of Calgary, Calgary, AB, Canada, ${ }^{2}$ Owerko Centre, Child Development Centre, Department \\ of Pediatrics, Cumming School of Medicine, Alberta Children's Hospital Research Institute, University of Calgary, Calgary, \\ $A B$, Canada, ${ }^{3}$ Department Community Health Sciences, Cumming School of Medicine, University of Calgary, Calgary, AB, \\ Canada, ${ }^{4}$ Department of Psychiatry, Cumming School of Medicine, University of Calgary, Calgary, AB, Canada, ${ }^{5}$ Ludmer \\ Centre for Neuroinformatics and Mental Health, Douglas Mental Health University Institute, McGill University, Montreal, QC, \\ Canada, ${ }^{6}$ Department of Psychiatry, Faculty of Medicine, McGill University, Montreal, QC, Canada, ${ }^{7}$ School of Nursing, \\ University of Northern British Columbia, Prince George, BC, Canada, ${ }^{8}$ Department of Biochemistry \& Molecular Biology, \\ University of Calgary, Calgary, AB, Canada, ${ }^{9}$ Department of Medical Genetics, University of Calgary, Calgary, AB, Canada
}

Attachment is a biological evolutionary system contributing to infant survival. When primary caregivers/parents are sensitive and responsive to their infants' needs, infants develop a sense of security. Secure infant attachment has been linked to healthy brain and organ-system development. Belsky and colleagues proposed the term differential susceptibility to describe context-dependent associations between genetic variations and behavioral outcomes as a function of parenting environments. Variations in the Cannabinoid Receptor Gene 1 (CNR1) are associated with memory, mood, and reward and connote differential susceptibility to more and less optimal parental caregiving quality in predicting children's behavioral problems.

Aim: To determine if parental caregiving quality interacts with children's expressionbased polygenic risk score (ePRS) for the CNR1 gene networks in the prefrontal cortex, striatum, and hippocampus in predicting the probability of attachment security and disorganized attachment.

Design: Prospective correlational methods examined maternal-infant pairs ( $n=142$ ) from which infants provided DNA samples at 3 months. Parental caregiving quality was assessed via the Child Adult Relationship Experiment (CARE)-index at 6 months, and attachment security via the Strange Situation Procedure at a mean age of 22 months. The CNR1 ePRSs include genes co-expressed with the CNR1 genes in the prefrontal cortex, striatum, or hippocampus, and were calculated using the effect size of the association between the individual single nucleotide polymorphisms 
from those genes and region-specific gene expression (GTEx). Logistic regression was employed (alpha $<0.05$, two-tailed) to examine the main and interaction effects between parental caregiving quality and ePRSs in predicting attachment patterns. Interpretation of results was aided by analyses that distinguished between differential susceptibility and diathesis-stress.

Results: Significant interactions were observed between (1) maternal sensitivity and ePRS in the striatum in predicting attachment security, (2) maternal unresponsiveness with the ePRS in the hippocampus in predicting disorganization, and (3) maternal controlling with the ePRS in the hippocampus in predicting disorganization.

Conclusion: These findings offer support for genetic differential susceptibility to the quality of maternal sensitivity in the context of the ePRS in the striatum. However, the significant interactions between hippocampal ePRS and maternal unresponsiveness and controlling in predicting the probability of disorganization were more suggestive of the diathesis-stress model.

Keywords: expression-based polygenic risk score (ePRS), cannabinoid receptor gene 1 (CNR1), parent-child relationship quality, CARE-index, strange situation procedure, APrON study, attachment security, attachment disorganization

\section{INTRODUCTION}

Since psychiatrist John Bowlby first considered the importance of infants' secure attachments with their caregivers to later mental health, research on attachment patterns has exploded (Sroufe et al., 2005; Cassidy, 2016). Attachment theory has not only provided a basis for international research programs but has also become an influential perspective on child development in clinical and welfare practice (Sroufe et al., 2005; Kozlowska and Elliott, 2014; Teti and Kim, 2014). The most fundamental aspect of attachment theory is that a child's attachment behavior has social-biological underpinnings promoting a vulnerable infant's proximity to the attachment figure, improving their chance of survival (Simpson, 1999; Cassidy, 2016). When primary caregivers/parents are available and responsive to their infants' needs, infants develop a sense of security, making them feel safe, secure, and protected (Bowlby, 1982; Benoit, 2004; Solomon and George, 2016). Infants anticipate their parents' responses to their distress and shape their attachment behaviors accordingly (Benoit, 2004). When observed and scored, infant attachment behavior typically is classified into one of four attachment patterns: secure, insecure-avoidant, insecureresistant, and disorganized (Ainsworth et al., 1978; Main and Solomon, 1986). A growing body of evidence links infant secure attachment patterns to healthy brain and organ-system development and insecure and disorganized attachment to increased levels of all-cause morbidity, chronic inflammation, coronary artery disease, and an array of mental health disorders (Schore, 2000, 2001; Sroufe, 2005; Puig et al., 2013).

Parental caregiving quality, typically characterized by qualities of maternal sensitivity, control, and responsiveness, predicts infants' attachment pattern (De Wolff and van Ijzendoorn, 1997; van Ijzendoorn et al., 1999; Madigan et al., 2006; Crittenden, 2010; Bailey et al., 2017). Sensitivity is a caregiver's ability to perceive, accurately interpret, and respond promptly and accurately to an infant's cues (Ainsworth et al., 1978). High maternal sensitivity involves responding to infant/child cues that signal needs or distress, such as fussiness due to hunger or fatigue, in a timely fashion, while low maternal sensitivity is indicated by low responsiveness (Barnard and Guralnick, 1997). High maternal sensitivity also denotes behaviors contrary to overtly or covertly hostile behaviors or attempts to excessively control infant behavior in routine interactions (Kelly et al., 2008). While sensitive caregiving may support the development of acceptable emotional expressions and optimal regulation, harsh, controlling caregiving behaviors may undermine children's emotional development. Therefore, high-quality parental caregiving is typically characterized by sensitive and responsive interactions attentive to infant needs while mitigating excessive intrusion and control. A greater degree of sensitivity shows the infant that the caregiver is dependable, which creates a secure base for the child then to explore the world (Thompson, 2016). Parental sensitivity is regarded as one of the most important determinants of infant attachment security (Fearon et al., 2006; BakermansKranenburg and van Ijzendoorn, 2007; Colmer et al., 2011), while traumatic events thought to undermine parental caregiving predict disorganized attachment (Lyons-Ruth, 2015).

However, despite being an important factor in predicting attachment patterns, parental caregiving quality does not explain as much variance as one might expect (De Wolff and van Ijzendoorn, 1997; van Ijzendoorn et al., 1999; Bailey et al., 2017). There has been evidence to support associations between attachment patterns and several sociodemographic factors such as maternal age (Esma et al., 2018), socioeconomic status (Acevedo et al., 2012), migration background (Keller, 2018), infant sex (Weinberg et al., 1999; David and Lyons-Ruth, 2005), infant gestational age (Wille, 1991), descriptive factors such as maternal depression (Kohlhoff and Barnett, 2013), social support (Jacobson and Frye, 1991), and infant birth weight (Wille, 1991; Weiss et al., 2000). In addition, there is a growing body of 
evidence suggesting that individuals' genetics may influence attachment patterns (Lakatos et al., 2000, 2002; Belsky and Beaver, 2011; Luijk et al., 2011; Belsky et al., 2015; Pappa et al., 2015; Golds et al., 2020). Specifically, disorganized attachment patterns have been linked to genetic variations of the genes responsible for regulating dopamine (DA; Lakatos et al., 2000, 2002; Gervai et al., 2005, 2007; van Ijzendoorn and BakermansKranenburg, 2006).

The majority of the literature examining the roles of parental caregiving behavior and genetics in predicting attachment relates to neurotransmitters, particularly those implicated in reward processing (Bakermans-Kranenburg and van Ijzendoorn, 2016; Feldman, 2017). DA is a neurotransmitter associated with motivation or pleasure necessary to promote a response to environmental cues that signal reward and depend on carrying out a specific action or behavior to receive it (Du Hoffmann and Nicola, 2014). The endocannabinoid system (ECS) is implicated in a wide variety of brain functions, such as reward processing as well as memory, mood, and motor control. The Type 1 Cannabinoid Receptor (CB1), encoded by the Cannabinoid Receptor 1 (CNR1) gene, is a key component of the endocannabinoid system and is expressed in both the central and peripheral nervous systems, particularly on axon terminals in the cerebellum, hippocampus, basal ganglia, frontal cortex, amygdala, hypothalamus, and midbrain (Romero-Fernandez et al., 2013; Brzosko et al., 2015). The CB1 receptor is an important component of the ECS in the nervous system, regulating synaptic transmission by modulating neurotransmitters' release, including DA (Tao et al., 2020). Two of the most commonly studied CNR1 polymorphisms include rs1049353 (Agrawal et al., 2012) and rs7766029 (Juhasz et al., 2009) in relation to different phenotypic outcomes, especially in the rs1049353 genotype, A allele. Previous studies support the notion that outcomes can vary with the different polymorphic variants of these genes. For example, when the CNR1-A allele is absent, the caregiving environment's impact on children's externalizing behaviors is attenuated. Higher levels of negative caregiver control, in the presence of the CNR1-A gene, predicted parent-report of more externalizing behaviors in children. In comparison, lower levels of negative caregiver control predicted the report of less externalizing behaviors in a differentially susceptible manner (Letourneau et al., 2019).

Genetic variations can have varying functional effects in different biological contexts; thus, specific genes may produce different observable outcomes in response to either stressful or protective environments (Del Giudice, 2016). Belsky and Pluess (2009a) proposed utilizing the term differential susceptibility when describing genes associated with both adaptive and maladaptive changes in phenotypes in response to "supportive" and "unsupportive" parental caregiving environments. Parental caregiving quality incorporates constructs such as nurturing, acceptance, and cohesion, and involves behaviors toward the child (e.g., praising, encouraging, and giving physical affection), which signal to the child love, support, and acceptance (Barnes et al., 2000). In short, genetic differential susceptibility theory may explain why some infants appear to have increased susceptibilities to parental caregiving qualities.
Genetic variation leading to neurobiological and temperamental traits characterized by highly sensitive and responsive stress physiology may determine increased susceptibility to stress and adversity (Del Giudice, 2016). Highly genetically susceptible children have disproportionately high morbidity rates when raised in adverse stressful environments; in addition, children with a higher degree of genetic susceptibility more frequently exhibit mental health symptoms in adolescence (Essex et al., 2011), exhibit epigenetic modifications (i.e., decreased DNA methylation; Goodman et al., 2018), and are more likely to exhibit behavioral problems under circumstances of low caregiver support (Skowron et al., 2014; Letourneau et al., 2019). In contrast, children with a high degree of genetic susceptibility become more socially integrated, have the lowest levels of illness (Boyce et al., 1995), and highest school engagement levels when receiving high-quality parental caregiving (Obradović et al., 2010). This dichotomy in children with a high degree of genetic susceptibility suggests a unique opportunity to identify individuals who could be at risk for poor health outcomes by assessing children's genetic differential susceptibility to parental caregiving quality. However, a rival explanation for some of these associations is diathesis-stress, in which poor developmental experiences (e.g., low-quality parenting) are most likely to impact the development of individuals who carry vulnerability factors that result in maladaptation. Ascertaining whether parenting interacts with genetic factors in either a differential susceptibility or diathesis-stress manner is a subject of ongoing exploration (Garmezy et al., 1984; Roisman et al., 2012; Portella et al., 2020).

Novel genomic metrics that either predict gene expression in tissue-specific regions or use gene co-expression information may provide a more comprehensive view of a specific gene or a gene network's role in modulating an individual's response to environmental variations, compared to that provided by the single candidate gene approach (Gamazon et al., 2015; Barth et al., 2020). Expression-based polygenic risk scores (ePRS) offer one such approach to understand the underlying genetic background linked to behavioral outcomes (Hari Dass et al., 2019). ePRS is a genomic risk profiling method that recognizes a gene network contribution to a particular condition or outcome derived from a combination of small effects from many genetic variants. ePRS scores are derived based on transcriptional co-expression profiles from specific regions of the mouse (GeneNetwork) and human (Brainspan) brains, used to identify Single Nucleotide Polymorphisms (SNPs) functionally associated with gene expression in the human brain (GTEx). ePRS analyses provide a new paradigm to identify gene-byenvironment interactions (McGrath et al., 2013; Plomin, 2013; Iyegbe et al., 2014; Silveira et al., 2017; Belsky et al., 2019; De Lima et al., 2020).

When attachments form in early infancy, activation and closer links are observed among neurobiological brain systems underpinning affiliation, reward, and stress management (UlmerYaniv et al., 2016). Functional magnetic resonance imaging (fMRI) has been used to investigate the brain activity associated with humans' various social attachments (Feldman, 2017). These fMRIs provide evidence for three main inter-connected neural systems that integrate to establish, maintain, and 
enhance our attachments to others, including the rewardmotivation system (Berridge and Robinson, 1998), the embodied simulation/empathy network (Gallese, 2014), and mentalizing processes (Frith and Frith, 2006). The reward-motivation system comprises the striatum (nucleus accumbens, caudate, and putamen), amygdala, ventral tegmental area, orbitofrontal cortex, ventromedial prefrontal cortex, and anterior cingulate cortex (ACC). The existence of convergent projections from the cortex to the striatum, along with hippocampal and amygdala-striatal projections, places the striatum as a central entry port for processing emotional/motivational information supporting human attachment (Haber and Knutson, 2010; Robinson et al., 2012; Pauli et al., 2016). The reward-motivation system employs DA and oxytocin rich pathways (Schultz, 2000; Berridge et al., 2009; Haber and Knutson, 2010) and supports multiple attachment-related motivational behaviors, such as social orienting, social seeking, and maintaining contact (Acevedo et al., 2012; Chevallier et al., 2012). Attachments have an intrinsic motivational value that combine immediate hedonic responses with approach motivation, goal-directed behavior, and learning (Berridge and Robinson, 1998).

The embodied simulation/empathy network includes the insula, ACC, inferior frontal gyrus, inferior parietal lobule, and supplementary motor area. Embodied simulation is an ancient evolutionary mechanism essential to grounding a 'shared world' in the brain and underpins the human capacity to build and maintain attachments (Craig, 2009; Gallese, 2014). Finally, the formation and maintenance of attachment bonds also rely on higher-order mentalizing processes that involve complex top-down inferences (Frith and Frith, 2006; Van Overwalle, 2009). Mentalizing processes underpin attachment and reinforce attachment formation by building on the individual's ability to appreciate multiple perspectives, understand others' goals and motives, and keep in mind their values and concerns (Ciaramidaro et al., 2014; Hari et al., 2015). The mentalizing system consists of frontotemporal-parietal structures, particularly the superior temporal sulcus, posterior cingulated cortex, temporoparietal junction, temporal pole, and medial prefrontal cortex (Feldman, 2017).

To the best of our knowledge, this is the first study that seeks to investigate if infant genetic susceptibility interacts with the quality of parental caregiving in predicting attachment patterns using observational measures. This understanding could offer empirical evidence of infants' physiological responsivity to positive (and negative) parental caregiving (Barth et al., 2020). We propose utilizing the innovative approach of ePRS to determine if parental caregiving quality (i.e., sensitivity, unresponsiveness, and controlling) interacts with children's ePRS for the prefrontal cortex, striatum, and hippocampus CNR1 gene networks in predicting the probability of secure and/or disorganized attachment. Previous studies examining various polymorphic variants, including CNR1, in relation to children's behavior have suggested that they have the potential to interact with environmental influences in a differentially susceptible manner (Young et al., 2002; Letourneau et al., 2019). Due to the activation of the neurobiological systems associated with the ECS that underpin affiliation, reward, stress management, responsiveness to the environment, and mood (Lupica et al., 2004; Ranganathan and D’Souza, 2006; Hill et al., 2009; Zuurman et al., 2009; Zanettini et al., 2011; Feldman, 2017), and thus potential to relate to attachment pattern formation in infancy (Berridge and Robinson, 1998; Acevedo et al., 2012; Chevallier et al., 2012), we chose this specific gene (CNR1) and tissue-specific networks for study. We focused on the prefrontal cortex due to its association with cognitive, emotional functions, impulse control, and adaptive behaviors (Morecraft and Yeterian, 2002; Bechara and Van Der Linden, 2005), and the striatum for its involvement in the reward motivation system and potential to relate to attachment formation in infancy specifically (Feldman, 2017). Convergent projections from the cortex to the striatum, along with hippocampal and amygdalastriatal projections, places the striatum as a central entry port for processing emotional/motivational information supporting human attachments (Haber and Knutson, 2010; Robinson et al., 2012; Pauli et al., 2016; Feldman, 2017). Finally, as part of the limbic system, the hippocampus was chosen for its spatial and emotional memory involvement. The hippocampus plays an essential role in social memory and consolidating declarative or explicit memories of facts or events that enable conscious recall from long-term memory (Campbell and Macqueen, 2004). The ability to recognize and memorize familiar conspecifics (social memory) is a critical aspect of social interactions in animals (McGraw and Young, 2010; Okuyama et al., 2014, 2016). As the hippocampus develops, the infant can recognize and remember their caregiver and begin to feel a sense of pleasure with them during engaging interactions (Chambers, 2017).

We hypothesize that within the three selected brain regions (i.e., prefrontal cortex, striatum, and hippocampus): (1) higher maternal sensitivity will interact with ePRS for the CNR1 gene networks in predicting a higher probability of secure attachment and reduced probability of disorganization, (2) higher maternal controlling will interact with ePRS for CNR1 gene networks in predicting a reduced probability of secure attachment and higher probability of disorganization, and (3) higher maternal unresponsiveness will interact with ePRS for CNR1 gene networks in predicting a reduced probability of secure attachment and higher probability of disorganization.

\section{MATERIALS AND METHODS}

This secondary analysis employs data from the Fetal Programming Study (Giesbrecht et al., 2017), a sub-study derived from the larger Alberta Pregnancy Outcomes and Nutrition (APrON) longitudinal cohort study (Kaplan et al., 2014), which ended enrollment in 2012. The Fetal Programming Study aimed to examine biomarkers of maternal stress during pregnancy and collect data on parent-infant interaction quality and attachment (Kaplan et al., 2014; Giesbrecht et al., 2017; Letourneau et al., 2017). Ethics approval was obtained from the Conjoint Health Research Board at the University of Calgary in Alberta, Canada. All participants in the study completed a process of informed consent prior to participating. For this 
project's scope, relevant data were collected at study visits during pregnancy and 3, 6, and 22 months postpartum.

\section{Participants and Recruitment}

Recruitment of 294 pregnant women into the Fetal Programming study took place between 2011 and 2012 in a large western Canadian city. Expectant mothers were recruited through media advertisements and maternity, ultrasound, family medicine, and obstetric clinics (Kaplan et al., 2014). To be eligible at enrollment, mothers: (1) were less than 22 weeks pregnant, (2) were 16 years of age or older, (3) were pregnant with a singleton, (4) reported abstaining from alcohol and tobacco during pregnancy, (5) reported not receiving a glucocorticoid medication during pregnancy, and (6) reported no known fetal complications. Mothers were excluded if they could not answer questions in English or planned to move out of the region during the study's timeframe (Kaplan et al., 2014). Of the 294 recruited participants in the Fetal Programming Study, 142 maternal infant-pairs provided an infant Deoxyribonucleic Acid (DNA) sample in the form of a buccal swab or blood sample with sufficient quantity to calculate ePRS and completed all assessments of maternal-infant relationship quality and attachment patterns (Thomas et al., 2017).

\section{Procedures and Measures}

Data were collected on mothers' demographic characteristics at enrollment and infant demographic characteristics at birth. Additional data were collected during pregnancy and postpartum on depression and social support. Blood was drawn, or buccal cells were collected from children at 3 months of age. Observational assessments of maternal-infant interaction quality (predictor) were conducted at 6 months of age and infant attachment pattern (outcome) at 22 months.

\section{Predictors}

To measure parental caregiving quality, we employed the Child Adult Relationship Experiment (CARE)-Index (Crittenden, 2010). It is valid with infants from birth up to 15 months (Crittenden and Bonvillian, 1984; Crittenden and DiLalla, 1988; Ward and Carlson, 1995; Leadbeater et al., 1996; Leventhal et al., 2004), and inter-rater reliability values range between $r=0.73$ and 0.95 (Leventhal et al., 2004; Azar et al., 2007). When the infants were 6 months of age, a 5-min observational procedure was carried out by videotaping the mother-infant pairs engaging in play with age-appropriate toys. Seven aspects of interaction behavior are assessed, including facial expression, verbal expression, positional and body contact, affection, turntaking, control, and activity choice. Total scores for parental sensitivity, controlling, and unresponsiveness are derived, ranging from 0-14 (Crittenden, 2010). Author Letourneau is a reliable CARE-Index coder and supervised the administration and blinded data coding. Trained, independent designates coded video recordings at Crittenden's laboratory, who achieved a 94.4\% inter-rater agreement on the three observable constructs. For each of the CARE-Index subscales (i.e., sensitivity, controlling, and unresponsiveness), three scoring category groups were created, including: "low" which included maternal-child dyads that scored less than one standard deviation below the calculated mean; "mean," which included maternal-child dyads that scored within one standard deviation above or below the calculated mean; and "high" which included maternal-child dyads that scored more than one standard deviation above the calculated mean. These categories enabled data in graphs and figures to be interpreted more readily.

To collect DNA for analysis, blood was drawn from infants at a study visit at 3 months of age. All samples were drawn by a certified phlebotomist using either a butterfly needle or a 25-gauge 3/4 inch infant needle. The blood samples were processed within $6 \mathrm{~h}$ of collection at the affiliated hospital genetics laboratory. This process involved spinning the vacutainer at 3,000 rotations per minute for $15 \mathrm{~min}$ to separate the plasma, buffy coat (i.e., leukocytes and platelets), and erythrocytes. The buffy coat was extracted using a pipette from the collection container, placed into a microcentrifuge tube, and stored at $-80^{\circ} \mathrm{C}$ for DNA extraction at a later date. Buccal epithelial cells (BEC) were also collected from infants if their blood draw yield was low or unobtainable. This was done by rubbing a sterile cytology brush up and down the infant's entire cheek ten times on two different swabs to ensure an adequate sample was obtained. The BEC and processed blood leukocytes were kept in short-term storage at $-80^{\circ} \mathrm{C}$ before DNA extraction. DNA extraction was done by cell lysis, followed by purification using the Gentra Puregene method (Qiagen, Venlo, Limburg, Netherlands). The samples were processed for DNA purification using the Autopure method (Qiagen, Venlo, Limburg, Netherlands) and processed further using the cell lysate program. Samples were left open to air allowing for evaporation of excess ethanol, and low-TE buffer was added to the tubes. After DNA extraction, the isolated DNA samples were stored at $4^{\circ} \mathrm{C}$ at the affiliated hospital genetics laboratory.

The genetic data were extracted using Illumina HumanCoreExome BeadChipVersion 1 and subjected to quality control (QC) procedure using PLINK 1.9 (Chang et al., 2015). SNPs with missing call rate $>5 \%$, minor allele frequency $(\mathrm{MAF})<5 \%$, or violation of Hardy-Weinberg equilibrium (HWE) with $p$-value $<1 \mathrm{e}-30$, as well as samples with missing call rate $>5 \%$, outliers on heterozygosity or sex mismatches were removed. This final data set included 179 subjects and 289,296 genotyped SNPs. Then we utilized the Sanger Imputation Service for imputation. After the post-imputation QC and the imputation accuracy filter (INFO-score) $>0.80$, the final data set included 23,752,992 SNPs.

To describe the population stratification, we performed principal component analysis using SMARTPCA (Patterson et al., 2006) on this pruned dataset of genotyped SNPs (with $\mathrm{r} 2<0.20$, sliding window of 50 and an increment of 5 SNPs).

The $e P R S$ was created considering genes co-expressed with the Cannabinoid Receptor (ePRS-CNR1) in the prefrontal cortex (see Figure 1), striatum (see Figure 2), and hippocampus (see Figure 3) according to the protocol previously described by Silveira et al. (2017) and Hari Dass et al. (2019). In summary, the genetic score was created using (a) Genenetwork ${ }^{1}$, (b) Brainspan ${ }^{2}$,

\footnotetext{
${ }^{1}$ http://genenetwork.org

${ }^{2}$ http://www.brainspan.org/rnaseq/search/index.html
} 


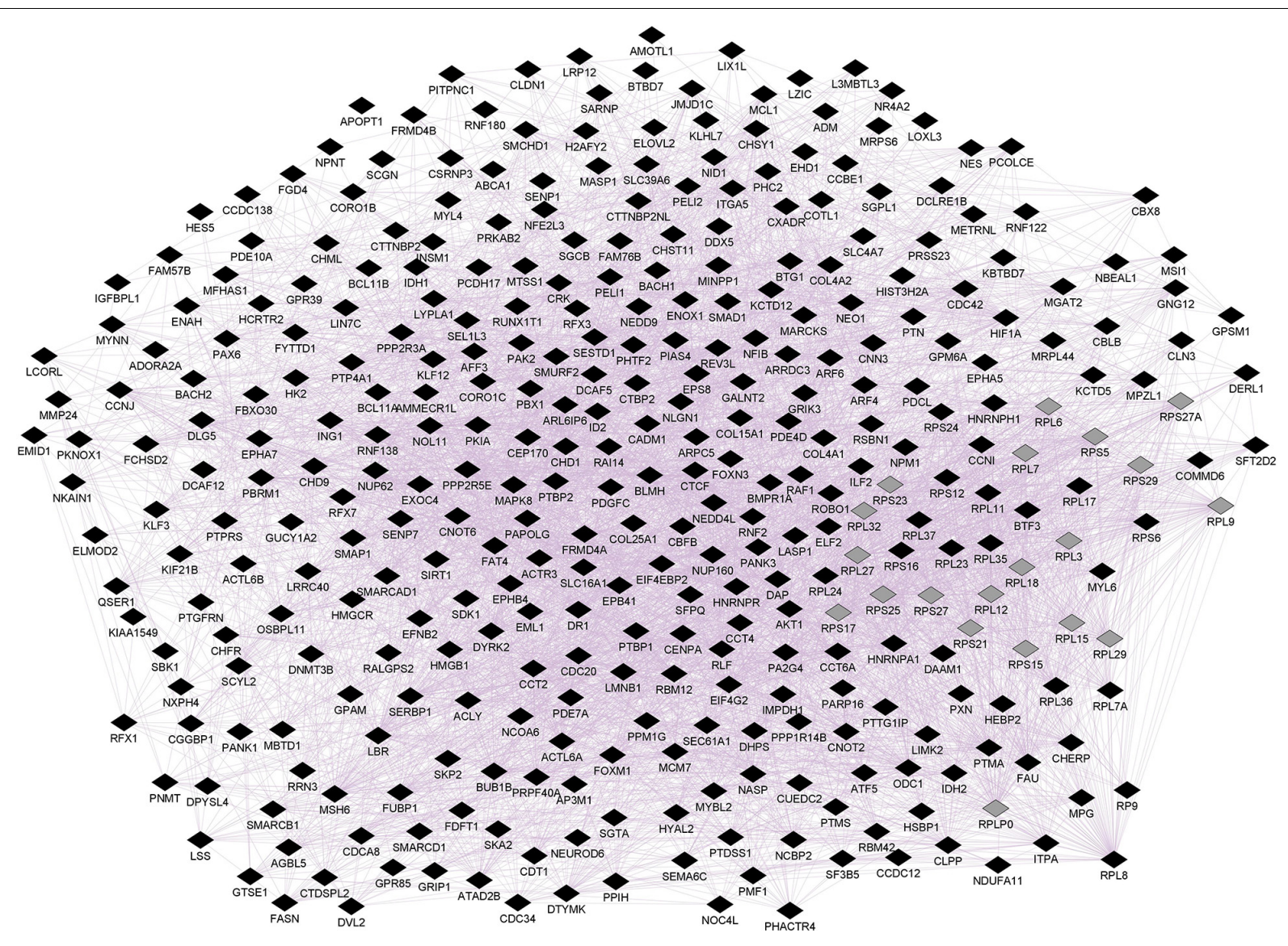

FIGURE 1 | Prefrontal CNR1 gene network using GeneMANIA. Black diamonds indicate query genes, whereas gray diamonds indicate related genes added by GeneMANIA. GeneMANIA converts mRNA expression data from Gene Expression Omnibus (GEO) to functional association networks, connecting co-expressed genes through purple lines. Node sizes represent gene scores, reflecting how often paths that start at a given gene node end up in one of the query genes.

and (c) GTEx ${ }^{3}$. In (a), we identified the transcriptional coexpression profiles of CNR1 (4,704 genes co-expressed with CNR1 in mice prefrontal cortex, 1,717 genes co-expressed with CNR1 in mice hippocampus, and 86 genes co-expressed with CNR1 in mice striatum $r>0.5$ ) (GeneNetwork). These genes were filtered by selecting those that were overexpressed during fetal/childhood (up to 5 years of age) at 1.5-fold more than adult gene expression in human postmortem samples (Brainspan). The final list included 343 genes for the CNR1 prefrontal gene network, 12 genes for the striatal network, and 175 genes for the hippocampal network. Based on the functional annotation of these genes in the National Center for Biotechnology Information, United States National Library of Medicine $^{4}$ using GRCh37.p13, we gathered all of the existing SNPs from these genes present on our data, merged this list with SNPs that were available on GTEx, and retained the resulting list of SNPs for linkage disequilibrium clumping $(r 2,0.25)$. The final lists of SNPs included 8506 independent functional SNPs for CNR1 prefrontal ePRS, 3446 SNPs for the hippocampal ePRS, and 434 SNPs for the striatal network. Based on the children's

${ }^{3}$ https://www.gtexportal.org/home/

${ }^{4}$ https://www.ncbi.nlm.nih.gov/variation/view/ genotype data, alleles at a given cis-SNP were weighed by the estimated effect of the genotype on gene expression (GTEx in which the effect allele is the alternative allele). Final ePRSs were obtained by summation over all SNPs accounting for the sign of correlation coefficient between the genes and CNR1 gene expression in the different regions. For inclusion in modeling, the CNR1 ePRS scores were standardized. Enrichment analysis of the gene networks was done using MetaCore ${ }^{\circledR}\left(\right.$ Clarivate Analytics $\left.^{5}\right)$. Cytoscape $^{\circledR}$ software (Shannon, 2003) and GeneMANIA app (Franz et al., 2018) were used to visualize the gene networks. The nodes are the elements of a network, and edges are the connection between these elements, that represent co-expression. Further, CNR1 ePRSs were then categorized into two groups, through a median split to characterize children into low or high ePRS groups.

\section{Outcome}

Attachment patterns were measured at a mean age of 22 months via the Strange Situation Procedure (SSP), the gold standard assessment for attachment patterns in infancy (Ainsworth et al., 1978). The coding scale was originally designed for children

${ }^{5}$ https://portal.genego.com/ 


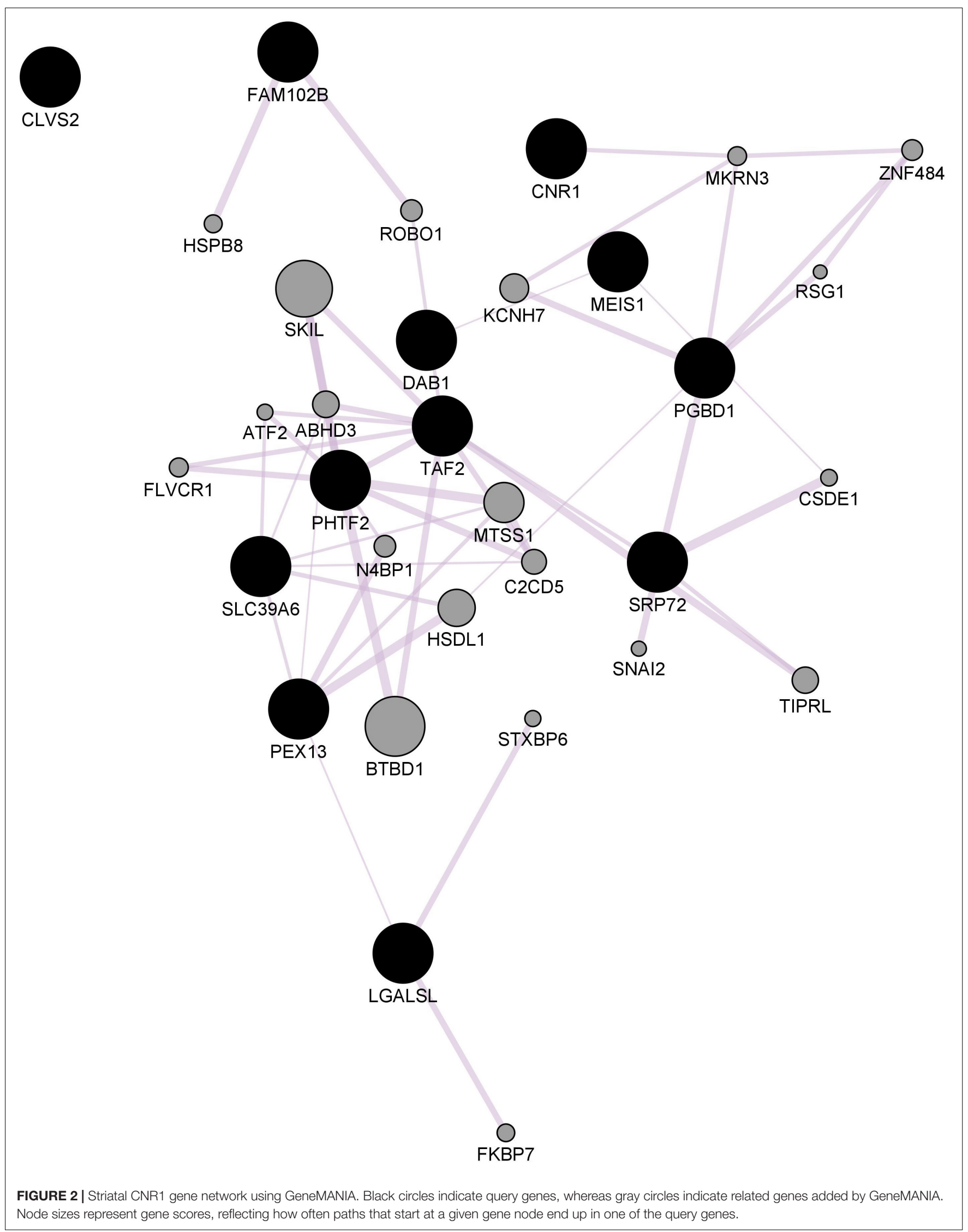




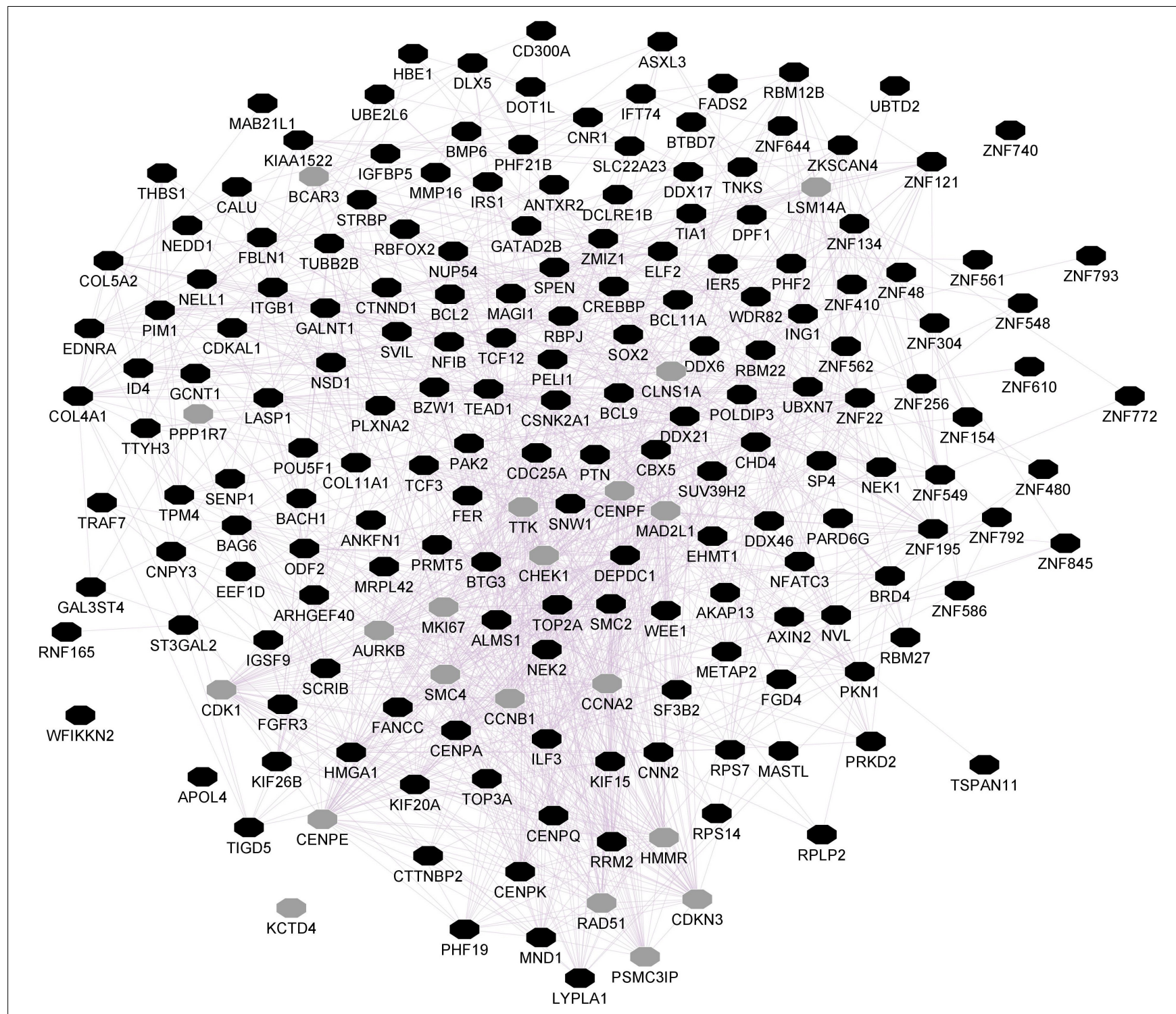

FIGURE 3 | Hippocampal CNR1 gene network using GeneMANIA. Black hexagons indicate query genes, whereas gray hexagons indicate related genes added by GeneMANIA. Node sizes represent gene scores, reflecting how often paths that start at a given gene node end up in one of the query genes.

between 12 and 20 months of age but is commonly used up to 24 months (Ainsworth et al., 1978; van IJzendoorn and Kroonenberg, 1988; Solomon and George, 2016). The SSP procedure contains eight brief episodes designed to activate infant's attachment behaviors by evoking mild levels of stress in children (e.g., seeking proximity to the parent) through a series of mother-child separations and reunions between the infant and mother and interactions between the infant and a 'stranger' (a research confederate), where the child's behaviors were observed through a two-way mirror and videorecorded for coding. A coder (Author Hart) deemed reliable by Alan Sroufe of the Institute of Child Development at the University of Minnesota (ABCD Model) and by Marinus van Ijzendoorn at Cambridge University (Type D) using the Main and Solomon Coding System, coded all SSP videotapes for patterns of attachment using standard categories of secure (B), insecure with subtypes avoidant (A) and resistant (C), and disorganized (D; Ainsworth et al., 1978; Main and Solomon, 1986). To attain a D code, Main's coding scheme was applied (Main and Stadtman, 1981; Main and Solomon, 1990), which assesses the degree of disorganized behavior in an interpretive way regarding conflict (e.g., aggressive outbursts) and/or disruptive behaviors (e.g., immobilized, disoriented, misdirected, behavior, sudden disordered activities, uninterpretable noises or movements) during the SSP. An expert coder at the Institute for Child Development also re-coded a random $15 \%$ of recordings. Cohen's kappa for inter-rater reliability was 0.73 . Due to the relatively small group sample sizes of insecure category subtypes (A and C) and disorganized (D), we dichotomized the sample into two groups, which is 
common in published research (Lewis-Morrarty et al., 2015; Fresno et al., 2018). The dichotomized groups used in the analyses were comprised of infants classified as secure (B) versus insecure (A, C, and $D)$ and disorganized $(D)$ versus organized (A, B, C).

\section{Covariates}

Demographic (i.e., maternal age, education, marital status, household income, country of birth; infant birth weight, gestational age, and sex) and descriptive (i.e., depression and social support) variables were considered. Mothers' perceptions of the quality of their partners' social support at 3, 6, and 22 months postnatal were assessed via the Social Support Effectiveness Questionnaire (SSEQ). The SSEQ is a 35 -item measure that evaluated the type (i.e., emotional/affirmational, informational, instrumental, and negative) and self-perceived effectiveness of the support mothers received from their partner or another support person. Total scores range from 0 to 80 , with higher scores indicating more effective support from partners. The internal consistency for this instrument is strong (Cronbach's alpha $=0.87$ ) when used to distinguish levels of social support for childbearing women (Rini et al., 2006; Stapleton et al., 2011; Giesbrecht et al., 2017). The Edinburgh Postnatal Depression Scale (EPDS) was employed at 3, 6, 12, and 22 months postpartum. On a 10-item self-administered scale, the parent is asked to select the number next to the response closest to how they have felt in the past 7 days. For women, the EPDS has been found to have high sensitivity (83.6\%) and specificity (88.3\%) for identifying depressive symptoms and the widely accepted cut-off of EPDS $\geq 10$, indicating at least probable minor depression (Pop et al., 1992; Matthey et al., 2006). We attempted to employ latent class analysis for both covariates to reduce the data collected at multiple time points (three times for social support, four times for depression). Only the analysis of social support revealed latent classes, categorized as high and low support. As no latent classes were identified for depression, we selected the maximum value on the depression scale over the four measurement time points and employed that value in analyses.

\section{Statistical Analyses}

First, the sample characteristics were analyzed with descriptive summaries, including frequencies, means, and standard deviations as appropriate. Second, univariate logistic regression associations between sample characteristics and attachment security/insecurity and disorganization/organization were examined to identify significant covariates for inclusion in the modeling that follows. Third, logistic regression modeling was employed to examine the main effects of the CARE-Index (sensitivity, controlling, and unresponsiveness) separately ( $X$ variable) using ePRS for CNR1gene networks in the prefrontal cortex, striatum, and hippocampus ( $Z$ variable; Model 2) and their interaction terms (Model 3), adjusting for principal components (PCs) for ancestry and sex of the child, along with any identified covariates above. We fitted each model to the data by maximum likelihood and ranked the models by their Akaike Information Criterion (AIC) to control for overfitting
(Akaike, 1973). Further, to aid in visualizing the results, we computed the unadjusted predicted probability of attachment pattern for each value of the parental caregiving quality predictors (CARE-Index sensitivity, controlling, and unresponsiveness) considering interaction with ePRS categorized into low (-1SD) and high $(+1 \mathrm{SD})$ scores.

\section{Analysis of Differential Susceptibility}

An additional step was performed in models with a significant interaction term to ensure that any observed differential susceptibility effects were not an artifact of imposing linear model assumptions on non-linear relationships (Model 4). Following the recommendations outlined by Roisman et al. (2012), additional linear regression models, including $X^{2}$ and $Z^{*} X^{2}$ as predictors, were created to verify that neither of these two terms were statistically significant. A post hoc analysis for the interaction terms in model 3 included analysis of

TABLE 1 | Sociodemographic and descriptive characteristics of study participants.

\begin{tabular}{|c|c|c|}
\hline Variables & Frequency & Percentages \\
\hline Maternal age in years [mean $(S D)]$ & $31.4[3.90]$ & \\
\hline Gestational age at birth in weeks [mean (SD)] & $39.34[1.57]$ & \\
\hline Birth weight in kilograms [mean (SD)] & $3.41[0.51]$ & \\
\hline \multicolumn{3}{|l|}{ Secure attachment } \\
\hline Yes & 68 & $47.9 \%$ \\
\hline No & 74 & $52.1 \%$ \\
\hline \multicolumn{3}{|l|}{ Disorganized attachment } \\
\hline Yes & 17 & $12.0 \%$ \\
\hline No & 125 & $88.0 \%$ \\
\hline \multicolumn{3}{|l|}{ Sex of child } \\
\hline Male & 72 & $50.7 \%$ \\
\hline Female & 70 & $49.3 \%$ \\
\hline \multicolumn{3}{|l|}{ Household income } \\
\hline Below $\$ 70,000$ & 26 & $18.3 \%$ \\
\hline$\$ 70,000$ or more & 116 & $81.7 \%$ \\
\hline \multicolumn{3}{|l|}{ Marital status } \\
\hline Single & 2 & $1.4 \%$ \\
\hline Married & 140 & $98.6 \%$ \\
\hline \multicolumn{3}{|l|}{ Ethnicity } \\
\hline Non-Caucasian & 24 & $16.9 \%$ \\
\hline Caucasian & 118 & $83.1 \%$ \\
\hline \multicolumn{3}{|l|}{ Born in Canada } \\
\hline No & 30 & $21.1 \%$ \\
\hline Yes & 112 & $78.9 \%$ \\
\hline \multicolumn{3}{|l|}{ Education level } \\
\hline Below degree & 43 & $30.3 \%$ \\
\hline Degree or more & 99 & $69.7 \%$ \\
\hline \multicolumn{3}{|l|}{ Social support (latent class) } \\
\hline Class 1 (low social support) & 72 & $50.7 \%$ \\
\hline Class 2 (high social support) & 70 & $49.3 \%$ \\
\hline \multicolumn{3}{|l|}{$\begin{array}{l}\text { Depressive symptoms max value }(3,6,12 \text {, and } \\
22 \text { months) }\end{array}$} \\
\hline EPDS $<9$ & 102 & $71.8 \%$ \\
\hline$E P D S \geq 10$ & 40 & $28.2 \%$ \\
\hline
\end{tabular}


Proportion of Interaction (PoI; i.e., the proportion of the total area represented in the interaction plots uniquely attributable to differential susceptibility) and Proportion Affected (PA; i.e., the proportion of the population that is differentially affected by the moderator $-Z$ variable; Roisman et al., 2012). The regions of significance (RoS) analyses were conducted using a Webbased program developed by Fraley ${ }^{6}$. Further, as per Roisman et al. (2012), evidence for differential susceptibility can be confirmed when the RoS analyses are performed to determine whether the moderator ( $Z$ variable) and the outcome variable are correlated at the low and high ends of the distribution of the predictor ( $X$ variable). Results should be considered significant only within a certain range of interest, that is $\pm 2 S D$ of the observed predictor variable. Values for the PoI index should be approximately within 0.40 and 0.60 , and for

${ }^{6} \mathrm{http}: / /$ www.yourpersonality.net/interaction the PA index should be close to 0.50 (Roisman et al., 2012; Portella et al., 2020).

\section{RESULTS}

Table 1 presents a descriptive analysis of the study variables. The mean age of mothers was $31.40(S D=3.90)$ years. The majority of women were married (98.6\%), had attained a university degree or more $(69.72 \%)$, and had household incomes $\geq \$ 70,000$ (81.69\%). Males made up approximately half of the sample of children (50.7\%), and most of the mothers were born in Canada (78.9\%). Less than half of children demonstrated a secure $(48 \%)$ rather than an insecure attachment pattern (52\%). Table 2 presents the results of the bivariate analyses of associations between predictors and attachment pattern, revealing that only birth weight significantly predicts disorganization.

TABLE 2 | Associations between predictors and attachment pattern.

\begin{tabular}{|c|c|c|c|c|c|c|}
\hline \multirow[t]{2}{*}{ Variables } & \multirow[t]{2}{*}{ Secure } & \multirow[t]{2}{*}{ Insecure } & \multirow{2}{*}{$\begin{array}{c}\text { OR } 95 \% \mathrm{Cl} \\
P \text {-value }\end{array}$} & \multirow{2}{*}{$\frac{\text { Not disorganized }}{[n(\%)]}$} & \multirow{2}{*}{$\begin{array}{c}\text { Disorganized } \\
{[n(\%)]}\end{array}$} & \multirow{2}{*}{$\begin{array}{c}\text { OR } 95 \% \mathrm{Cl} \\
P \text {-value }\end{array}$} \\
\hline & & & & & & \\
\hline $\begin{array}{l}\text { Maternal age in years } \\
\text { [mean }(S D)]\end{array}$ & $31.69(3.97)$ & $31.13(3.8)$ & $\begin{array}{c}1.04(0.95,1.13) \\
p=0.393\end{array}$ & $31.43(3.81)$ & $31.17(4.66)$ & $\begin{array}{c}0.98(0.86,1.12) \\
p=0.769\end{array}$ \\
\hline Gestational age at birth & $39.41(1.24)$ & $39.28(1.8)$ & $1.05(0.85,1.29)$ & $39.41(1.52)$ & $38.87(1.88)$ & $0.82(0.62,1.10)$ \\
\hline Birth in weeks [mean $(S D)]$ & & & $p=0.639$ & & & $p=0.185$ \\
\hline $\begin{array}{l}\text { Birth weight in } \mathrm{kg} \text { [mean } \\
(S D)]\end{array}$ & $3.48(0.48)$ & $3.34(0.54)$ & $\begin{array}{c}1.74(1.89,3.36) \\
p=0.101\end{array}$ & $3.45(0.49)$ & $3.07(0.57)$ & $\begin{array}{c}0.23(0.08,0.65) \\
\boldsymbol{p}=\mathbf{0 . 0 0 5}\end{array}$ \\
\hline ePRS CNR1 & $-0.15(0.90)$ & $0.14(1.06)$ & $\begin{array}{c}0.74(0.53,1.04) \\
p=0.087\end{array}$ & $-0.07(0.97)$ & $0.55(1.08)$ & $\begin{array}{c}1.97(1.13,3.43) \\
\boldsymbol{p}=\mathbf{0 . 0 1 7}\end{array}$ \\
\hline Maternal sensitivity & $5.19(1.75)$ & $5.33(2.27)$ & $\begin{array}{c}0.96(0.69,1.34) \\
p=0.806\end{array}$ & $5.32(1.89)$ & $5.0(3.01)$ & $\begin{array}{c}0.65(0.38,1.15) \\
p=0.139\end{array}$ \\
\hline Maternal controlling & $2.70(3.68)$ & $2.61(3.46)$ & $\begin{array}{c}0.97(0.70,1.35) \\
p=0.856\end{array}$ & $2.52(3.47)$ & $3.75(4.02)$ & $\begin{array}{c}1.42(0.89,2.25) \\
p=0.139\end{array}$ \\
\hline Maternal unresponsiveness & $6.07(3.45)$ & $6.05(3.71)$ & $\begin{array}{c}1.05(0.75,1.46) \\
p=0.783\end{array}$ & $6.14(3.58)$ & $5.25(3.49)$ & $\begin{array}{c}0.84(0.51,1.39) \\
p=0.510\end{array}$ \\
\hline \multicolumn{7}{|l|}{ Sex } \\
\hline Male & $31(45.59)$ & $41(55.41)$ & $1.48(0.76,2.87)$ & $64(51.20)$ & $8(47.06)$ & $1.16(0.42,3.20)$ \\
\hline Female & $37(54.41)$ & $33(44.59)$ & $p=0.243$ & $61(48.80)$ & $9(52.94)$ & $p=0.748$ \\
\hline \multicolumn{7}{|l|}{ Household income } \\
\hline Below $\$ 70,000$ & $12(17.65)$ & $14(18.92)$ & $1.09(0.46,2.55)$ & $21(16.80)$ & $5(29.41)$ & $0.48(0.15,1.51)$ \\
\hline$\$ 70,000$ or more & $56(82.35)$ & $60(81.08)$ & $p=0.845$ & $104(83.20)$ & $12(70.59)$ & $p=0.207$ \\
\hline \multicolumn{7}{|l|}{ Born in Canada } \\
\hline No & $15(22.06)$ & $15(20.27)$ & $0.89(0.40,2.01)$ & $25(20.0)$ & $5(29.41)$ & $0.59(0.19,1.84)$ \\
\hline Yes & $53(77.94)$ & $59(79.73)$ & $p=0.794$ & $100(80.0)$ & $12(70.59)$ & $p=0.372$ \\
\hline \multicolumn{7}{|l|}{ Education level } \\
\hline Below university degree & $22(32.35)$ & $21(28.38)$ & $0.83(0.40,1.69)$ & $38(30.40)$ & $5(29.41)$ & $1.03(0.34,3.14)$ \\
\hline University degree or more & $46(67.65)$ & $53(71.62)$ & $p=0.607$ & $87(69.60)$ & $12(70.59)$ & $p=0.934$ \\
\hline \multicolumn{7}{|c|}{ Maternal depression (max value) } \\
\hline Not depressed & $47(69.12)$ & $54(73.97)$ & $1.27(0.61,2.64)$ & $93(73.81)$ & $9(56.25)$ & $2.19(0.76,6.35)$ \\
\hline Depressed & $21(30.88)$ & $19(26.03)$ & $P=0.523$ & $33(26.19)$ & $7(43.75)$ & $p=0.148$ \\
\hline \multicolumn{7}{|l|}{ Social support (latent class) } \\
\hline Low social support & $36(53.73)$ & $36(48.65)$ & $0.82(0.42,1.58)$ & $66(52.80)$ & $6(35.29)$ & $2.05(0.71,5.89)$ \\
\hline High social support & $31(46.27)$ & $38(51.35)$ & $p=0.547$ & $59(47.20)$ & $11(64.71)$ & $p=0.176$ \\
\hline
\end{tabular}

Bolded indicates a $p$ value of less than 0.05 . 


\section{ePRS CNR1 Prefrontal Cortex}

Hypothesis 1. We hypothesized that higher maternal sensitivity would interact with CNR1 ePRS in the prefrontal cortex in predicting a higher probability of secure attachment and reduced probability of disorganization, controlling for covariates. With respect to the probability of attachment security or disorganization, logistic regression revealed no significant associations in any model (results not shown).

Hypothesis 2. We hypothesized that higher maternal controlling would interact with CNR1 ePRS in the prefrontal cortex in predicting a reduced probability of secure attachment and a higher probability of disorganization. With respect to both attachment security and disorganization, logistic regression revealed no significant interactions (results not shown).

Hypothesis 3. We hypothesized that higher maternal unresponsiveness would interact with CNR1 ePRS in the prefrontal cortex to predict a reduced probability of secure attachment and a higher probability of disorganization. With respect to both attachment security and disorganization, logistic regression revealed no significant interactions (results not shown).

\section{ePRS CNR1 Striatum}

Hypothesis 1. We hypothesized that higher maternal sensitivity would interact with CNR1 ePRS in the striatum in predicting a higher probability of secure attachment and reduced probability of disorganization, controlling for covariates. We observed a significant interaction between striatum CNR1 ePRS and maternal sensitivity in predicting the probability of attachment security in the fully adjusted model 3 (see Table 3). This model complied with a differential susceptibility assessment, given that the crossover point was within the limits of the $X$ variable (maternal sensitivity) and indices were near expected values $(\mathrm{PoI}=0.67, \mathrm{PA}=0.63)$. See Figure 4 for the graphed associations. With respect to the probability of disorganization, logistic regression revealed no significant associations in any model (results not shown).

Hypothesis 2. We hypothesized that higher maternal controlling would interact with CNR1 ePRS in the striatum in predicting a reduced probability of secure attachment and a higher probability of disorganization. With respect to both attachment security and disorganization, logistic regression revealed no significant interactions (results not shown).

Hypothesis 3. We hypothesized that higher maternal unresponsiveness would interact with CNR1 ePRS in

TABLE 3 | Associations among maternal sensitivity, striatal gene network for CNR1ePRS, covariates, and secure vs. insecure attachment pattern.

\begin{tabular}{|c|c|c|c|c|}
\hline Variables & $\begin{array}{c}\text { Model } 1 \\
\text { Adjusted OR (95\% Cl) }\end{array}$ & $\begin{array}{c}\text { Model } 2 \\
\text { Adjusted OR (95\% Cl) }\end{array}$ & $\begin{array}{c}\text { Model } 3 \\
\text { Adjusted OR }(95 \% \mathrm{Cl})\end{array}$ & $\begin{array}{c}\text { Model } 4 \\
\text { Adjusted OR }(95 \% \mathrm{Cl})\end{array}$ \\
\hline Maternal sensitivity & $\begin{array}{c}0.93(0.67,1.31) \\
p=0.693\end{array}$ & - & $\begin{array}{c}0.93(0.64,1.34) \\
p=0.929\end{array}$ & $\begin{array}{c}\text { 4.8- }(0.57,40.31) \\
\quad p=0.148\end{array}$ \\
\hline Maternal sensitivity² & - & - & - & $\begin{array}{c}0.92(0.83,1.02) \\
p=0.123\end{array}$ \\
\hline Striatal_ePRS & - & $\begin{array}{c}0.90(0.64,1.26) \\
p=0.542\end{array}$ & $\begin{array}{c}0.86(0.59,1.23) \\
p=0.414\end{array}$ & $\begin{array}{c}1.05(0.65,1.70) \\
p=0.829\end{array}$ \\
\hline $\begin{array}{l}\text { Maternal } \\
\text { sensitivity }^{2} \times \text { striatal ePRS }\end{array}$ & - & - & - & $\begin{array}{c}0.71(0.44,1.13) \\
p=0.152\end{array}$ \\
\hline Female & $\begin{array}{c}1.51(0.77,2.94) \\
p=0.227\end{array}$ & $\begin{array}{c}0.64(0.33,1.25) \\
p=0.193\end{array}$ & $\begin{array}{c}0.59(0.29,1.19) \\
p=0.144\end{array}$ & $\begin{array}{c}1.64(0.81,3.34) \\
p=0.167\end{array}$ \\
\hline PC3 & - & $\begin{array}{c}0.01(0.00,19.42) \\
p=0.250\end{array}$ & $\begin{array}{c}0.01(0.00,11.31) \\
p=0.191\end{array}$ & $\begin{array}{c}0.0(0.00,6.75) \\
p=0.141\end{array}$ \\
\hline AIC & 201.07 & 204.90 & 203.03 & 200.39 \\
\hline Pol & - & - & 0.67 & - \\
\hline Crossover point & & - & -0.34 & - \\
\hline PA index & - & - & 0.63 & - \\
\hline
\end{tabular}

Cl, confidence interval; OR, odds ratio. PC 1, 2, 3, principal component for ancestry; AlC, Akaike Information Criterion; Pol, proportion of interaction; PA, proportion affected; inf, very large $\mathrm{Cl}$ and $\mathrm{OR}$; bold refers to $p<0.05$. Logistic regression modeling for main effects of the sensitivity ( $X$ variable; model 1) using ePRS for CNR1 gene networks in the striatum (Z variable; model 2) and their interaction terms (Model 3), adjusting for principal components (PCs) for ancestry and sex of the child. Model fit statistics (AIC; model) confirmed that Model 3 was optimal. Bolded indicates a p value of less than 0.05. 


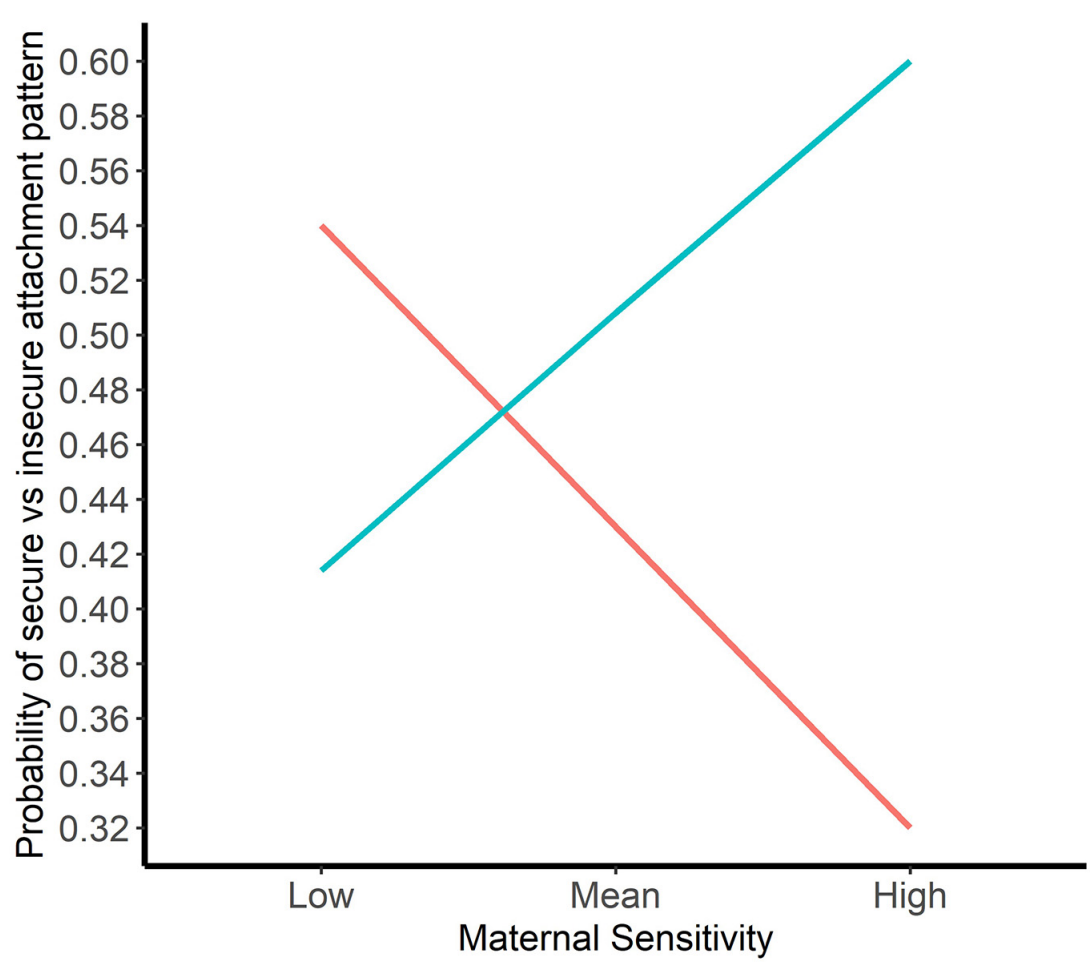

Sample - High ePRS - Low ePRS

FIGURE 4 | Interaction between Striatal Gene Network and Maternal Sensitivity in Predicting Attachment. Shows that higher maternal sensitivity and a low CNR1 ePRS in the striatum predicts a higher probability of secure attachment. Higher maternal sensitivity and a high CNR1 ePRS in the striatum predicts a lower probability of secure attachment.

the striatum to predict a reduced probability of secure attachment and a higher probability of disorganization. With respect to both attachment security and disorganization, logistic regression revealed no significant interactions (results not shown).

\section{ePRS CNR1 Hippocampus}

Hypothesis 1. We hypothesized that higher maternal sensitivity would interact with CNR1 ePRS in the hippocampus in predicting a higher probability of secure attachment and reduced probability of disorganization, controlling for covariates. With respect to both attachment security and disorganization, logistic regression revealed no significant interactions (results not shown).

Hypothesis 2. We hypothesized that higher maternal controlling would interact with CNR1 ePRS in the hippocampus to predict a higher probability of insecure attachment and a higher probability of disorganization, controlling for covariates. With respect to the probability of attachment security (results not shown), logistic regression revealed no significant associations in any model. However, we observed a significant interaction between hippocampal CNR1 ePRS and maternal controlling behavior in predicting the probability of disorganization in the fully adjusted model
3 (see Table 4). This model did not comply with the criteria for differential susceptibility, given that the cross over point was not near the midpoint of $X$ or even within the limits of the $X$ variable (maternal controlling) and indices were outside of expected values ( $\mathrm{PoI}=0.16, \mathrm{PA}=0.22$ ), suggesting that this interaction is more indicative of diathesis-stress. See Figure 5 for the graphed associations.

Hypothesis 3. We hypothesized that higher maternal unresponsiveness would interact with CNR1 ePRS in the hippocampus in predicting a higher probability of insecure attachment and higher probability of disorganization, controlling for covariates. With respect to the probability of attachment security, logistic regression revealed no significant associations in any model (results not shown). We observed a significant interaction between hippocampal CNR1 ePRS and maternal unresponsiveness in predicting the probability of disorganization in the fully adjusted model 3 (see Table 5). See Figure 6 for the graphed association. This model did not comply with the criteria for the differential susceptibility model, given that the cross over point was not near the midpoint of $X$ or even within the limits of the $X$ Variable (maternal unresponsiveness) and indices were outside of expected values $(\mathrm{PoI}=0.73, \mathrm{PA}=0.68)$, suggesting that this interaction is more indicative of diathesis-stress. 


\section{Gene Network Analysis}

Enrichment analysis demonstrated the prefrontal CNR1 gene network is enriched for gene ontology terms related to nervous system development (FDR q $=7.493 \mathrm{e}-16)$, regulation of neuron differentiation (FDR $\mathrm{q}=1.958 \mathrm{e}-13$ ), and neurogenesis (FDR $\mathrm{q}=2.514 \mathrm{e}-13)$. The hippocampal network is enriched for gene ontology terms related to regulation of transcription (FDR $\mathrm{q}=1.757 \mathrm{e}-21)$ and regulation of metabolic processes (FDR $\mathrm{q}=1.022 \mathrm{e}-21)$. The striatal network is enriched for GO terms related to transcription initiation (FDR $\mathrm{q}=7.619 \mathrm{e}-9)$, histone acetylation (FDR $\mathrm{q}=2.124 \mathrm{e}-5$ ), and the cannabinoid signaling pathway (FDR q $=4.786 \mathrm{e}-4)$.

\section{DISCUSSION}

This study set out to analyze if parental caregiving qualities (i.e., sensitivity, controlling, and unresponsiveness) interacted with the ePRS for the CNR1 gene networks in the prefrontal cortex, striatum, and hippocampus in predicting the probability of secure or disorganized attachment patterns. We hypothesized that higher sensitivity, lower controlling, and lower unresponsiveness would interact with ePRS for CNR1 in these three brain regions in predicting a higher probability of secure attachment and reduced probability of disorganization. Results for the prefrontal cortex failed to reject the null hypotheses for interaction effects between sensitivity, unresponsiveness, and controlling with CNR1 ePRS on either security of attachment or disorganization. Within the striatum, we observed a significant interaction between maternal sensitivity and CNR1 ePRS in predicting attachment security. We observed that higher maternal sensitivity and a low CNR1 ePRS in the striatum predicted a higher probability of secure attachment. The opposite is true for high CNR1 ePRS; higher maternal sensitivity and a high CNR1 ePRS in the striatum predicts a lower probability of secure attachment. Within the hippocampus, we observed a significant interaction between both unresponsiveness and controlling with the CNR1 ePRS in predicting disorganization. Higher maternal controlling and a higher CNR1 ePRS in the hippocampus predicted a lower probability of disorganization, and higher maternal controlling with a lower CNR1 ePRS predicted a higher probability of disorganization. Finally, we observed that high maternal unresponsiveness coupled with a low CNR1 ePRS in the hippocampus predicted a lower probability of disorganization and higher maternal unresponsiveness with a high CNR1 ePRS predicted a higher probability of disorganization.

In summary, low CNR1 ePRS in the striatum, a region of the brain involved in the reward motivation system, predicted

TABLE 4 | Associations among maternal controlling, hippocampal gene network for ePRS, covariates, and disorganized versus organized attachment pattern.

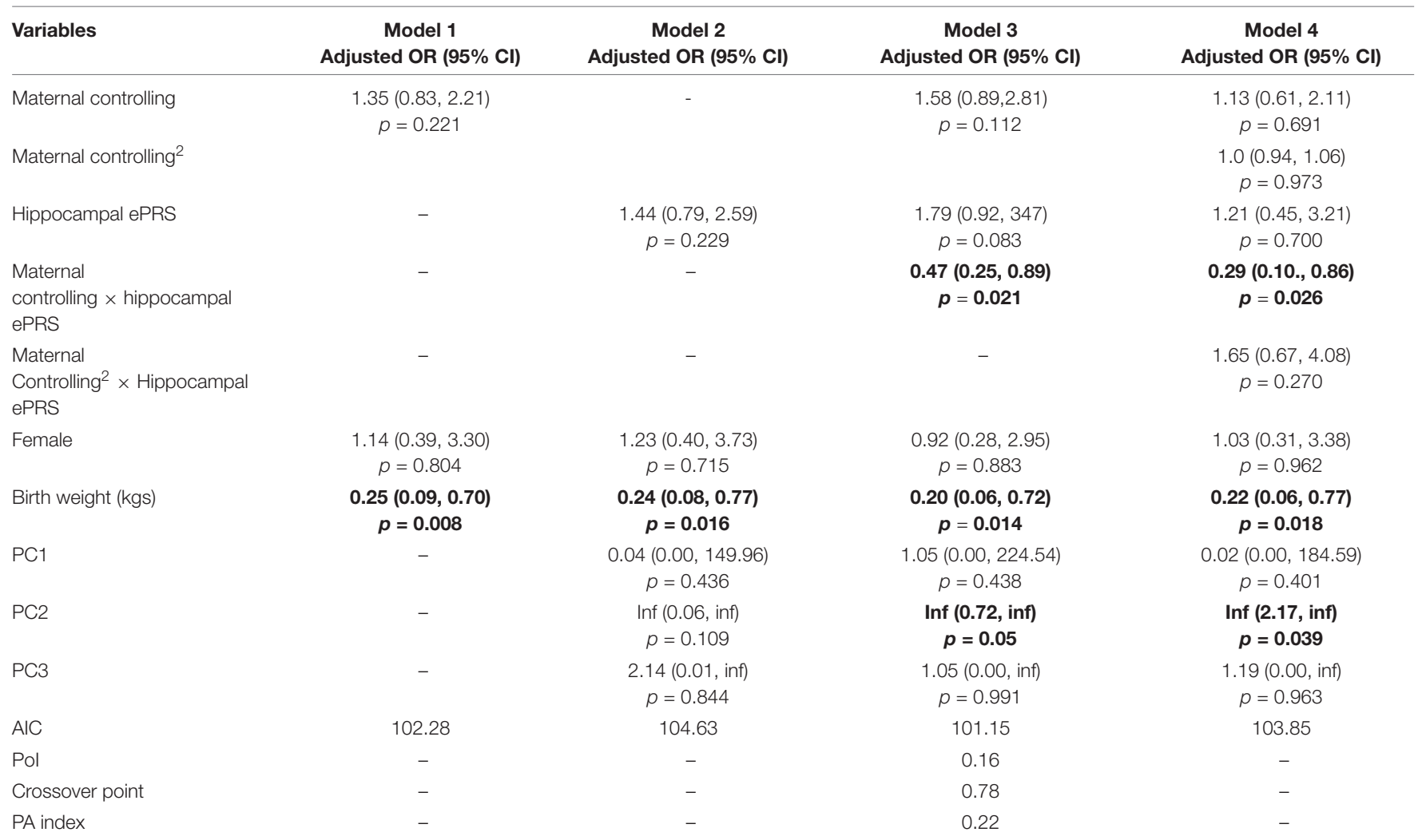

Cl, confidence interval; OR, odds ratio. PC 1, 2, 3, principal component for ancestry; AlC, Akaike Information Criterion; Pol, proportion of interaction; PA, proportion affected; inf, very large $\mathrm{Cl}$ and $\mathrm{OR}$; bold refers to $\mathrm{p}<0.05$. Logistic regression modeling for main effects of the controlling (X variable; Model 1$)$ using ePRS for CNR1 gene networks in the hippocampus (Z variable; Model 2) and their interaction terms (Model 3), adjusting for principal components (PCs) for ancestry and sex of the child. Model fit statistics (AIC) confirmed that Model 3 was optimal. Bolded indicates a $p$ value of less than 0.05. 


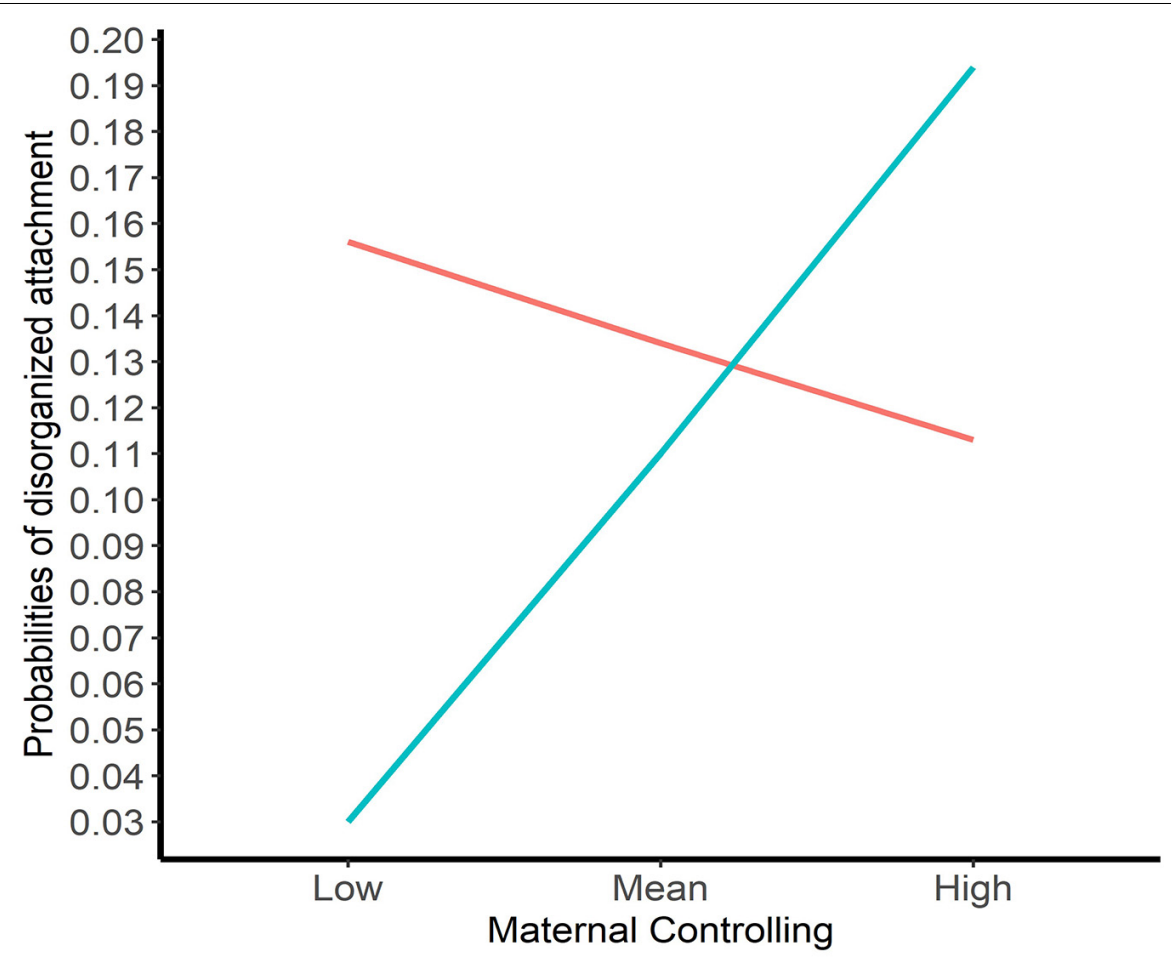

Sample - High ePRS - Low ePRS

FIGURE 5 | Interaction between Hippocampal Gene Network and Maternal Controlling in Disorganized Attachment. Shows that higher maternal controlling and a high CNR1 ePRS in the hippocampus predicts a lower probability of disorganization. Higher maternal controlling and a low CNR1 ePRS in the hippocampus predicts a higher probability of disorganization.

a greater likelihood of secure attachment in the context of more optimal parental caregiving (i.e., greater sensitivity). Within the hippocampus, a region of the brain known for its involvement in spatial and emotional memory, suboptimal parental caregiving (i.e., greater degrees of controlling and unresponsive parental behavior) predicted a decreased likelihood of disorganized attachment with a high CNR1 ePRS with respect to maternal controlling and a low CNR1 ePRS with respect to maternal unresponsiveness. Our findings offer support for the genetic differential susceptibility to the quality of maternal sensitivity within the context of the CNR1 ePRS in the striatum, as suggested by Belsky (1997), who theorized that children may differ in their receptiveness to parenting influences. However, in the case of the significant interactions between hippocampal CNR1 ePRS and maternal unresponsiveness and controlling in predicting the probability of disorganization, the analyses carried out to confirm differential susceptibility were more suggestive of the diathesis-stress model. The diathesis-stress model suggests that poor developmental experiences (e.g., low-quality parenting) will have the greatest impact on the development of individuals who carry vulnerability factors (e.g., genetic polymorphisms), which are latent diatheses that result in maladaptation when "turned on" by poor environmental experiences (Garmezy et al., 1984; Roisman et al., 2012). These findings are consistent when examining the role that genetics may play in how children form attachments, as other studies have observed that parenting particularly affected children with various polymorphisms of genes that regulate the DA system (i.e., DAT1 9- and 10-repeat and Dopamine Receptor D4 7-repeat) and reward sensitivity (Bakermans-Kranenburg et al., 2008; Bosmans et al., 2020). Our findings further support the notion that multiple genes may make a child more or less susceptible to their caregiving environment (Belsky and Beaver, 2011; Roisman et al., 2012), but in a manner consistent with either differential susceptibility or diathesis-stress, given the brain region under study.

Attachment is a relationship between infants and their caregivers, representing a brain-based biological evolutionary system promoting infant survival (Ainsworth et al., 1978; Chisholm, 1996). In attachment pattern formation, activation is observed among the neurobiological systems underpinning affiliation, reward, and stress management (Ulmer-Yaniv et al., 2016). These observations are likely a result of the intrinsic motivational value that combines the immediate hedonic responses in developing bonds with approach motivation, goaldirected behavior, and learning (Berridge and Robinson, 1998). Our findings related to the CNR1 gene network in the prefrontal cortex, striatum, and hippocampus corroborates the associations between the genetic variations within the ECS and attachment 
pattern formations. When primary caregivers/parents provide a supportive environment, infants develop a sense of security, making them feel safe, secure, and protected (Bowlby, 1982; Benoit, 2004; Solomon and George, 2016). In contrast, evidence suggests that disorganized attachment is predicted by suboptimal parenting and can lead to child behavioral and lifespan mental health problems (Main and Solomon, 1990; Lakatos et al., 2000, 2002; Sroufe, 2005; Puig et al., 2013).

The CNR1 gene networks within the prefrontal cortex, striatum, and hippocampus were chosen to be examined within the context of differential susceptibility, yet findings also pointed to the diathesis-stress model. CNR1 gene has been identified through extensive research as having polymorphisms associated with different observable outcomes (e.g., externalizing behavior and self-regulation) in response to differences in parenting/caregiving qualities (Belsky and Pluess, 2009b; Belsky and Beaver, 2011). In addition, these gene networks were examined within these brain regions because of the existence of convergent projections from the cortex to the striatum, along with hippocampal and amygdala-striatal projections, that places the striatum as a central entry port for processing emotional/motivational information in supporting the development of human attachments (Feldman, 2017). While several studies have focused on the effects of specific variations of these genes in relation to behavior and self-regulation (Belsky and Pluess, 2009b; Belsky and Beaver, 2011; Letourneau et al., 2019), this is the first study to our knowledge that not only examines the associations between these genes and attachment patterns but also utilizes ePRS to predict the probability of disorganized attachment patterns. Our findings suggest that it is important to consider both the ePRS and the brain region when looking at a child's susceptibility to their caregiving environment and provide promise for examining these gene networks in other regions of the brain or other gene networks where a candidate gene approach has been associated with varying attachment patterns and differential susceptibility or diathesis-stress [e.g., dopamine receptor D4 gene (DRD4) and a disorganized attachment pattern; Lakatos et al., 2000; Bakermans-Kranenburg and van Ijzendoorn, 2016].

Attachment theory provides a framework that explains the influence of early social experiences on normal and problematic development (Lakatos et al., 2000). Even in the case of adopted children who are not biologically related to their parents, it was found that early mother-infant interactions and attachment patterns predicted later socialemotional and cognitive development (Stams et al., 2002).

TABLE $\mathbf{5}$ | Associations among maternal unresponsiveness, hippocampal gene network for ePRS, covariates, and disorganized versus organized attachment pattern.

\begin{tabular}{|c|c|c|c|c|}
\hline Variables & $\begin{array}{c}\text { Model } 1 \\
\text { Adjusted OR (95\% Cl) }\end{array}$ & $\begin{array}{c}\text { Model } 2 \\
\text { Adjusted OR }(95 \% \mathrm{Cl})\end{array}$ & $\begin{array}{c}\text { Model } 3 \\
\text { Adjusted OR (95\% Cl) }\end{array}$ & $\begin{array}{c}\text { Model } 4 \\
\text { Adjusted OR (95\% Cl) }\end{array}$ \\
\hline Maternal unresponsiveness & $\begin{array}{c}0.88(0.51,1.49) \\
p=0.629\end{array}$ & - & $\begin{array}{c}0.69(0.36,1.32) \\
p=0.261\end{array}$ & $\begin{array}{c}4.45(0.41,47.88) \\
p=0.218\end{array}$ \\
\hline Maternal unresponsiveness ${ }^{2}$ & - & - & - & $\begin{array}{c}0.94(0.88,1.01) \\
p=0.088\end{array}$ \\
\hline Hippocampal ePRS & - & $\begin{array}{c}1.44(0.79,2.59) \\
p=0.229\end{array}$ & $\begin{array}{c}1.57(0.81,3.03) \\
p=0.182\end{array}$ & $\begin{array}{c}1.17(0.51,2.68) \\
p=0.700\end{array}$ \\
\hline $\begin{array}{l}\text { Maternal } \\
\text { unresponsiveness } \times \text { hippocampal } \\
\text { ePRS }\end{array}$ & - & - & $\begin{array}{c}2.56(1.29,5.08) \\
p=0.007\end{array}$ & $\begin{array}{c}4.36(1.78,10.64) \\
p=0.001\end{array}$ \\
\hline $\begin{array}{l}\text { Maternal } \\
\text { unresponsiveness }{ }^{2} \times \text { hippocampal } \\
\text { ePRS }\end{array}$ & - & - & - & $\begin{array}{c}2.08(0.95,4.52) \\
p=0.065\end{array}$ \\
\hline Female & $\begin{array}{c}1.12(0.39,3.19) \\
p=0.843\end{array}$ & $\begin{array}{c}1.23(0.40,3.73) \\
p=0.715\end{array}$ & $\begin{array}{c}0.96(0.30,3.08) \\
p=0.949\end{array}$ & $\begin{array}{c}0.98(0.28,3.40) \\
p=0.983\end{array}$ \\
\hline Birth weight (kgs) & $\begin{array}{c}0.24(0.08,0.67) \\
p=0.006\end{array}$ & $\begin{array}{c}0.24(0.08,0.77) \\
p=0.016\end{array}$ & $\begin{array}{c}0.16(0.04,0.61) \\
p=0.007\end{array}$ & $\begin{array}{c}0.13(0.03,0.53) \\
p=0.004\end{array}$ \\
\hline PC1 & - & $\begin{array}{c}0.04(0.00,149.96) \\
p=0.436\end{array}$ & $\begin{array}{c}0.05(0.00,376.37) \\
p=0.509\end{array}$ & $\begin{array}{c}(0.00,196.55) \\
p=0.378\end{array}$ \\
\hline PC2 & - & $\begin{array}{l}\operatorname{lnf}(0.06, \text { inf }) \\
p=0.109\end{array}$ & $\begin{array}{c}\operatorname{Inf}(1.99, \text { inf }) \\
p=0.119\end{array}$ & $\begin{array}{l}\text { Inf }(361.76, \text { inf }) \\
\qquad p=0.010\end{array}$ \\
\hline PC3 & - & $\begin{array}{c}2.14 \text { (0.01, inf }) \\
p=0.844\end{array}$ & $\begin{array}{c}0.74(0.001,2.14 \mathrm{E}+7) \\
p=0.940\end{array}$ & $\begin{array}{c}0.05(0.00,356.35) \\
p=0.519\end{array}$ \\
\hline $\mathrm{AIC}$ & 103.50 & 104.64 & 99.71 & 98.04 \\
\hline Pol & - & - & 0.73 & - \\
\hline Crossover point & - & - & -0.48 & - \\
\hline PA index & - & - & -0.68 & - \\
\hline
\end{tabular}

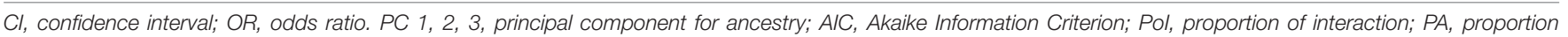

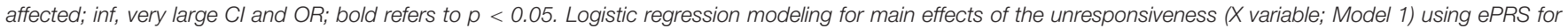

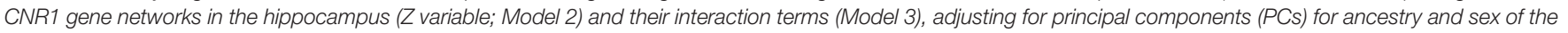
child. Model fit statistics (AIC) confirmed that Model 3 was optimal. Bolded indicates a p value of less than 0.05. 


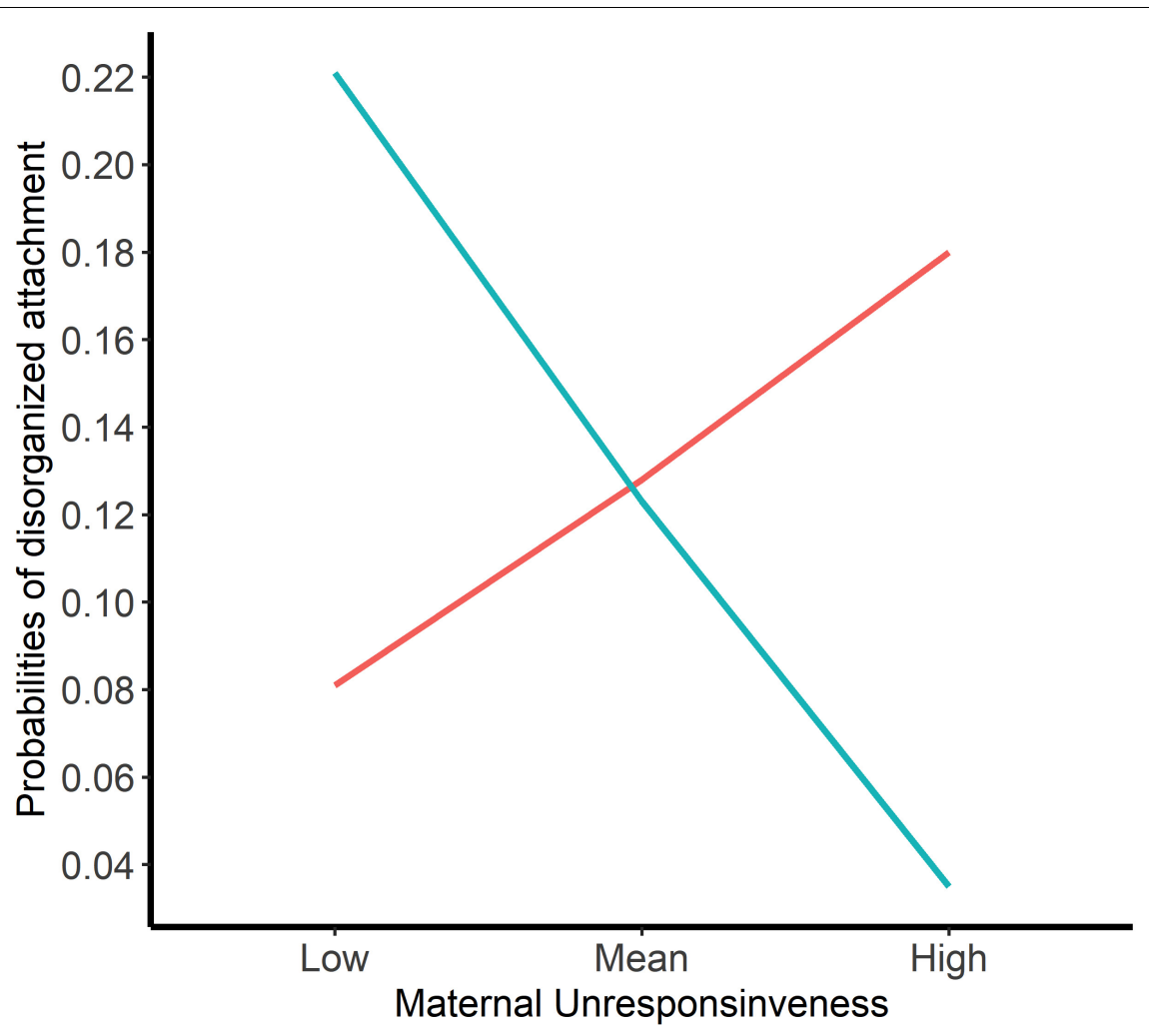

Sample - High ePRS - Low ePRS

FIGURE 6 | Interaction between Hippocampal Gene Network and Maternal Unresponsiveness in Disorganized Attachment. Shows that high maternal unresponsiveness and a low CNR1 ePRS in the hippocampus predict a lower probability of disorganization. Higher maternal unresponsiveness and a high CNR1 ePRS in the hippocampus predict a higher probability of disorganization.

Disorganized infant-parent attachment has become an area of significant interest to researchers and clinicians due to its clear associations with lifespan developmental and psychological disorders (Newman et al., 2015). We have demonstrated that variations among the CNR1 gene networks in the various brain regions (i.e., prefrontal cortex, striatum, and hippocampus) demonstrated different findings in predicting secure and disorganized attachment (De Wolff and van Ijzendoorn, 1997; van Ijzendoorn et al., 1999; Madigan et al., 2006; Crittenden, 2010; Cyr et al., 2010; Leerkes, 2011; Bailey et al., 2017). Understanding genetic factors that may affect the security of an infant's attachment with the mother may help identify those at risk for attachment disorganization by adding predictive possibility (Bakermans-Kranenburg and van Ijzendoorn, 2007). Failure to consider a child's genotype and differential susceptibility (or diathesis-stress) to experiences (e.g., caregiver sensitivity, responsiveness, and controlling) may pose a barrier to understanding the broader set of predictors of secure attachment pattern and undermine interventions aimed at changing a child's socioenvironmental exposures.

\section{Limitations and Strengths}

This study has many strengths, including the prospective design and observational assessments of maternal-child relationship quality (i.e., sensitivity) and attachment patterns; however, there are several limitations to note. First, the sample that we employed for this secondary data analysis is highly educated (69.72\% of mothers having a university degree) as compared with the provincial $(28.2 \%)$ and national $(28.5 \%)$ averages, which may limit generalizability (Letourneau et al., 2019; Statistics Canada, 2020). Further, the majority of women were married (98.6\%) and had household income $\geq \$ 70,000$ (81.69\%). Finally, parity or the presence of siblings for each child was not factored into the analysis, potentially affecting the maternal perception of infant cues, thereby affecting maternal sensitivity (Rutherford et al., 2017). In addition, only "maternal" caregiving quality was assessed; however, rather than seeking to reinforce gender stereotypes, we recognize that primary caregivers may be mothers, fathers, or others. We also recognize that in Canada (Findlay and Kohen, 2012) and in our study (Kaplan et al., 2014), the majority of primary caregivers of infants are mothers. 


\section{CONCLUSION}

To the best of our knowledge, this is the first study that examines the interaction between maternal parental caregiving qualities (i.e., sensitivity, controlling, and unresponsiveness) and children's ePRS for the CNR1 gene networks in the prefrontal cortex, striatum, and hippocampus in predicting the probability of secure and disorganized attachment patterns in young children. This research provides a foundation to explore genetic susceptibilities to varying caregiving environments in predicting attachment patterns and other outcomes. This research also provides a starting point for exploring other gene networks and influences on children's differential susceptibility to their environments. Promoting secure attachment patterns is a public health goal, as it is associated with lifelong health and a reduced likelihood of all-cause morbidity, chronic inflammation, coronary artery disease, and an array of mental disorders. Further research in the area may allow practitioners to target interventions to support those most at risk for insecure or disorganized attachment, thereby reducing the risk for negative life-long sequelae.

\section{DATA AVAILABILITY STATEMENT}

The data generated for this study is subject to the following licenses/restrictions: Privacy and Confidentiality of Participants. Requests to access these datasets should be directed to NL, nicole.letourneau@ucalgary.ca.

\section{ETHICS STATEMENT}

The studies involving human participants were reviewed and approved by University of Calgary Conjoint Health Research

\section{REFERENCES}

Acevedo, B. P., Aron, A., Fisher, H. E., and Brown, L. L. (2012). Neural correlates of long-term intense romantic love. Soc. Cogn. Affect. Neurosci. 7, 145-159. doi: 10.1093/scan/nsq092

Agrawal, A., Nelson, E. C., Littlefield, A. K., Bucholz, K. K., Degenhardt, L., Henders, A. K., et al. (2012). Cannabinoid receptor genotype moderation of the effects of childhood physical abuse on anhedonia and depression. Arch. Gen. Psychiatry 69, 732-740. doi: 10.1001/archgenpsychiatry.20 11.2273

Ainsworth, M. D. S., Blehar, M. C., Waters, E., and Wall, S. (1978). Patterns of Attachment: A Psychological Study of the Strange Situation. Mahwah, NJ: Erlbaum.

Akaike, H. (ed.) (1973). Information Theory, and an Extension of the Maximum Likelihood Principle. Budapest: Akadémiai Kiadó.

Azar, R., Paquette, D., Zoccolillo, M., Baltzer, F., and Tremblay, R. E. (2007). The association of major depression, conduct disorder, and maternal overcontrol with a failure to show a cortisol buffered response in 4-month-old infants of teenage mothers. Biol. Psychiatry 62, 573-579. doi: 10.1016/j.biopsych.2006.11. 009

Bailey, H. N., Bernier, A., Bouvette-Turcot, A., Tarabulsy, G. M., Pederson, D. R., and Becker-Stoll, F. (2017). Deconstructing maternal sensitivity: predictive
Ethics Board. Written informed consent to participate in this study was provided by the participants' legal guardian/next of kin.

\section{AUTHOR CONTRIBUTIONS}

AP-D contributed to data analysis and graphing of genes, wrote and edited the drafts. NL devised the project, conceived the research questions, oversaw data collection, analysis and graphing of figures, and organized, wrote, and edited the drafts. PS contributed by generating the co-expression gene networks, genotyping data $\mathrm{QC}$ and polygenic scores calculation. HN conducted the data analysis, described the analysis and results, and prepared all tables. AK and SD reviewed drafts and offered substantive guidance. $\mathrm{MH}$ collected data essential to this project and described the measurement. GG contributed to data collection, reviewed drafts, and offered substantive guidance. All authors contributed to the article and approved the submitted version.

\section{ACKNOWLEDGMENTS}

We are extremely grateful to all the families who took part in this study and the whole APrON team (APrONstudy.ca), including investigators, research assistants, graduate and undergraduate students, volunteers, clerical staff and mangers. This cohort was established by an interdisciplinary team grant from Alberta Innovates Health Solutions (formally the Alberta Heritage Foundation for Medical Research). Additional funding from the Alberta Children's Hospital Foundation for Dr. Nicole Letourneau's Chair in Parent-Infant Mental Health enabled the collection and analysis of data presented in this manuscript.

relations to mother-child attachment in home and laboratory settings. Soc. Dev. 26, 679-693. doi: 10.1111/sode. 12220

Bakermans-Kranenburg, M. J., and van Ijzendoorn, M. H. (2007). Research review: genetic vulnerability or differential susceptibility in child development: the case of attachment. J. Child Psychol. Psychiatry 48, 1160-1173. doi: 10.1111/j.14697610.2007.01801.x

Bakermans-Kranenburg, M. J., and van Ijzendoorn, M. H. (2016). "Attachment, parenting, and genetics," in Handbook of Attachment: Theory, Research, and Clinical Applications, 3rd Edn, eds J. Cassidy and P. R. Shaver (New York, NY: The Guilford Press), 155-179.

Bakermans-Kranenburg, M. J., Van Ijzendoorn, M. H., Pijlman, F. T. A., Mesman, J., and Juffer, F. (2008). Experimental evidence for differential susceptibility: dopamine D4 receptor polymorphism (DRD4 VNTR) moderates intervention effects on toddlers' externalizing behavior in a randomized controlled trial. Dev. Psychol. 44, 293-300. doi: 10.1037/0012-1649.44.1.293

Barnard, K., and Guralnick, M. J. (1997). "Influencing parentchild interactions for children at risk," in The Effectiveness of Early Interventions, ed. M. J. Guralnick (Toronto: Paul Brookes).

Barnes, G. M., Reifman, A. S., Farrell, M. P., and Dintcheff, B. A. (2000). The effects of parenting on the development of adolescent alcohol misuse: a six-wave latent growth model. J. Marriage Fam. 62, 175-186. doi: 10.1111/j.1741-3737.2000. 00175.x 
Barth, B., Bizarro, L., Miguel, P. M., Dube, L., Levitan, R., O’Donnell, K., et al. (2020). Genetically predicted gene expression of prefrontal DRD4 gene and the differential susceptibility to childhood emotional eating in response to positive environment. Appetite 148:104594. doi: 10.1016/j.appet.2020.104594

Bechara, A., and Van Der Linden, M. (2005). Decision-making and impulse control after frontal lobe injuries. Curr. Opin. Neurol. 18, 734-739.

Belsky, J. (1997). Variation in susceptibility to environmental influence: an evolutionary argument. Psychol. Inq. 8, 182-186. doi: 10.1207/s15327965pli0 803_3

Belsky, J., and Beaver, K. M. (2011). Cumulative-genetic plasticity, parenting and adolescent self-regulation. J. Child Psychol. Psychiatry 52, 619-626. doi: 10.1111/ j.1469-7610.2010.02327.x

Belsky, J., Newman, D. A., Widaman, K. F., Rodkin, P., Pluess, M., Fraley, R. C., et al. (2015). Differential susceptibility to effects of maternal sensitivity? A study of candidate plasticity genes. Dev. Psychopathol. 27, 725-746. doi: 10.1017/ S0954579414000844

Belsky, J., and Pluess, M. (2009a). Beyond diathesis stress: differential susceptibility to environmental influences. Psychol. Bull. 135, 885-908. doi: 10.1037/ a 0017376

Belsky, J., and Pluess, M. (2009b). The nature (and nurture?) of plasticity in early human development. Perspect. Psychol. Sci. 4, 345-351. doi: 10.1111/j.17456924.2009.01136.x

Belsky, J., Pokhvisneva, I., Rema, A. S. S., Broekman, B. F. P., Pluess, M., O’Donnell, K. J., et al. (2019). Polygenic differential susceptibility to prenatal adversity. Dev. Psychopathol. 31, 439-441. doi: 10.1017/s0954579418000378

Benoit, D. (2004). Infant-parent attachment: definition, types, antecedents, measurement and outcome. Paediatr. Child Health 9, 541-545. doi: 10.1093/ pch/9.8.541

Berridge, K. C., and Robinson, T. E. (1998). What is the role of dopamine in reward: hedonic impact, reward learning, or incentive salience? Brain Res. Rev. 28, 309-369. doi: 10.1016/s0165-0173(98)00019-8

Berridge, K. C., Robinson, T. E., and Aldridge, J. W. (2009). Dissecting components of reward: 'liking', 'wanting', and learning. Curr. Opin. Pharmacol. 9, 65-73. doi: 10.1016/j.coph.2008.12.014

Bosmans, G., Bakermans-Kranenburg, M. J., Vervliet, B., Verhees, M. W. F. T., and van Ijzendoorn, M. H. (2020). A learning theory of attachment: unraveling the black box of attachment development. Neurosci. Biobehav. Rev. 113, 287-298. doi: 10.1016/j.neubiorev.2020.03.014

Bowlby, J. (1982). Attachment and Loss (Vol. 1: Attachment). New York, NY: Basic Books.

Boyce, W. T., Chesney, M., Alkon, A., Tschann, J. M., Adams, S., Chesterman, B., et al. (1995). Psychobiologic reactivity to stress and childhood respiratory illnesses: results of two prospective studies. Psychos. Med. 57, 411-422.

Brzosko, Z., Schultz, W., and Paulsen, O. (2015). Retroactive modulation of spike timing-dependent plasticity by dopamine. eLife 4:e09685. doi: 10.7554/eLife. 09685

Campbell, S., and Macqueen, G. (2004). The role of the hippocampus in the pathophysiology of major depression. J. Psychiatry Neurosci. 29, 417-426.

Cassidy, J. (2016). “The nature of the child's ties," in Handbook of Attachment: Theory, Research, and Clinical Applications, 3rd Edn, eds J. Cassidy and P. R. Shaver (New York, NY: The Guilford Press), 3-24.

Chambers, J. (2017). The neurobiology of attachment: from infancy to clinical outcomes. Psychodyn. Psychiatry 45, 542-563. doi: 10.1521/pdps.2017.45.4.542

Chang, C. C., Chow, C. C., Tellier, L. C., Vattikuti, S., Purcell, S. M., and Lee, J. J. (2015). Second-generation PLINK: rising to the challenge of larger and richer datasets. Gigascience 4:7. doi: 10.1186/s13742-0150047-8

Chevallier, C., Kohls, G., Troiani, V., Brodkin, E. S., and Schultz, R. T. (2012). The social motivation theory of autism. Trends Cogn. Sci. 16, 231-239. doi: 10.1016/j.tics.2012.02.007

Chisholm, J. (1996). The evolutionary ecology of attachment organization. Hum. Nat. 7, 1-37. doi: 10.1007/BF02733488

Ciaramidaro, A., Becchio, C., Colle, L., Bara, B. G., and Walter, H. (2014). Do you mean me? Communicative intentions recruit the mirror and the mentalizing system. Soc. Cogn. Affect. Neurosci. 9, 909-916. doi: 10.1093/scan/ nst062

Colmer, K., Rutherford, L., and Pam, M. (2011). Attachment theory and primary caregiving [Article]. Austral. J. Early Childhood 36, 16-20. doi: 10.1177/ 183693911103600403
Craig, A. D. (2009). How do you feel - now? The anterior insula and human awareness. Nat. Rev. Neurosci. 10, 59-70. doi: 10.1038/nrn2555

Crittenden, P. M. (2010). CARE-Index Infants Coding Manual. Miami, FL: Family Relations Institute.

Crittenden, P. M., and Bonvillian, J. D. (1984). The relationship between maternal risk status and maternal sensitivity. Am. J. Orthopsychiatry 54, 250-262. doi: 10.1111/j.1939-0025.1984.tb01492.x

Crittenden, P. M., and DiLalla, D. L. (1988). Compulsive compliance: the development of an inhibitory coping strategy in infancy. J. Abnorm. Child Psychol. 16, 585-599. doi: 10.1007/bf00914268

Cyr, C., Euser, E. M., Bakermans-Kranenburg, M. J., and Van Ijzendoorn, M. H. (2010). Attachment security and disorganization in maltreating and high-risk families: a series of meta-analyses. Dev. Psychopathol. 22, 87-108. doi: 10.1017/ s0954579409990289

David, D. H., and Lyons-Ruth, K. (2005). Differential attachment responses of male and female infants to frightening maternal behavior: tend or befriend versus fight of flight? Infant Mental Health J. 26, 1-18. doi: 10.1002/imhj.20033

De Lima, R. M. S., Barth, B., Arcego, D. M., De Mendonça Filho, E. J., Clappison, A., Patel, S., et al. (2020). Amygdala 5-HTT gene network moderates the effects of postnatal adversity on attention problems: anatomo-functional correlation and epigenetic changes. Front. Neurosci. 14:198. doi: 10.3389/fnins.2020.00198

De Wolff, M. S., and van Ijzendoorn, M. H. (1997). Sensitivity and attachment: a meta-analysis on parental antecedents of infant attachment. Child Dev. 68, 571-591. doi: 10.1111/j.1467-8624.1997.tb04218.x

Del Giudice, M. (2016). Differential susceptibility to the environment: are developmental models compatible with the evidence from twin studies? Dev. Psychol. 52, 1330-1339. doi: 10.1037/dev0000153

Du Hoffmann, J., and Nicola, S. M. (2014). Dopamine invigorates reward seeking by promoting cue-evoked excitation in the nucleus accumbens. J. Neurosci. 34, 14349-14364. doi: 10.1523/jneurosci.3492-14.2014

Esma, G., Oznur, K., and Kamile, K. (2018). Identification of factors affecting mother-infant bonding in advanced maternal age. Lupine Online J. Nurs. Health Care 1:102. doi: 10.32474/LOJNHC.2018.01.000102

Essex, M. J., Armstrong, J. M., Burk, L. R., Goldsmith, H. H., and Boyce, W. T. (2011). Biological sensitivity to context moderates the effects of the early teacher-child relationship on the development of mental health by adolescence. Dev. Psychopathol. 23, 149-161. doi: 10.1017/S0954579410000702

Fearon, R. P., van Ijzendoorn, M. H., Fonagy, P., Bakermans-Kranenburg, M. J., Schuengel, C., and Bokhorst, C. L. (2006). In search of shared and nonshared environmental factors in security of attachment: a behavior-genetic study of the association between sensitivity and attachment security. Dev. Psychol. 42, 1026-1040. doi: 10.1037/0012-1649.42.6.1026

Feldman, R. (2017). The neurobiology of human attachments. Trends Cogn. Sci. 21, 80-99. doi: 10.1016/j.tics.2016.11.007

Findlay, L. C., and Kohen, D. E. (2012). Leave practices of parents after the birth or adoption of young children. Can. Soc. Trends 94, 3-12.

Franz, M., Rodriguez, H., Lopes, C., Zuberi, K., Montojo, J., Bader, G. D., et al. (2018). GeneMANIA update 2018. Nucleic Acids Res. 46, W60-W64. doi: 10. 1093/nar/gky311

Fresno, A., Spencer, R., and Espinoza, C. (2018). Does the type of abuse matter? Study on the quality of child attachment narratives in a sample of abused children. J. Child Adolesc. Trauma 11, 421-430. doi: 10.1007/s40653-0170182-8

Frith, C. D., and Frith, U. (2006). The neural basis of mentalizing. Neuron 50, 531-534. doi: 10.1016/j.neuron.2006.05.001

Gallese, V. (2014). Bodily selves in relation: embodied simulation as second-person perspective on intersubjectivity. Philos. Trans. R. Soc. B Biol. Sci. 369:20130177. doi: $10.1098 /$ rstb.2013.0177

Gamazon, E. R., Wheeler, H. E., Shah, K. P., Mozaffari, S. V., Aquino-Michaels, K., Carroll, R. J., et al. (2015). A gene-based association method for mapping traits using reference transcriptome data. Nat. Genet. 47, 1091-1098. doi: 10.1038/ng. 3367

Garmezy, N., Masten, A. S., and Tellegen, A. (1984). The study of stress and competence in children: a building block for developmental psychopathology. Child Dev. 55, 97-111.

Gervai, J., Nemoda, Z., Lakatos, K., Ronai, Z., Toth, I., Ney, K., et al. (2005). Transmission disequilibrium tests confirm the link between DRD4 gene polymorphism and infant attachment. Am. J. Med. Genet. B Neuropsychiatr. Genet. 132, 126-130. doi: 10.1002/ajmg.b.30102 
Gervai, J., Novak, A., Lakatos, K., Toth, I., Danis, I., Ronai, Z., et al. (2007). Infant genotype may moderate sensitivity to maternal affective communications: attachment disorganization, quality of care, and the DRD4 polymorphism. Soc. Neurosci. 2, 307-319. doi: 10.1080/17470910701391893

Giesbrecht, G. F., Letourneau, N. L., and Campbell, T. S. (2017). Sexually dimorphic and interactive effects of prenatal maternal cortisol and psychological distress on infant cortisol reactivity. Dev. Psychopathol. 29, 805-818. doi: 10.1017/S0954579416000493

Golds, L., De Kruiff, K., and Macbeth, A. (2020). Disentangling genes, attachment, and environment: a systematic review of the developmental psychopathology literature on gene-environment interactions and attachment. Dev. Psychopathol. 32, 357-381. doi: 10.1017/s0954579419000142

Goodman, S. J., Roubinov, D. S., Bush, N. R., Park, M., Farré, P., Emberly, E., et al. (2018). Children's biobehavioral reactivity to challenge predicts DNA methylation in adolescence and emerging adulthood. Dev. Sci. 22:e12739. doi: 10.1111/desc. 12739

Haber, S. N., and Knutson, B. (2010). The reward circuit: linking primate anatomy and human imaging. Neuropsychopharmacology 35, 4-26. doi: 10.1038/npp. 2009.129

Hari, R., Henriksson, L., Malinen, S., and Parkkonen, L. (2015). Centrality of social interaction in human brain function. Neuron $88,181-193$. doi: 10.1016/j. neuron.2015.09.022

Hari Dass, S. A., McCracken, K., Pokhvisneva, I., Chen, L. M., Garg, E., Nguyen, T. T. T., et al. (2019). A biologically-informed polygenic score identifies endophenotypes and clinical conditions associated with the insulin receptor function on specific brain regions. EBioMedicine 42, 188-202. doi: 10.1016/j. ebiom.2019.03.051

Hill, M. N., McLaughlin, R. J., Morrish, A. C., Viau, V., Floresco, S. B., Hillard, C. J., et al. (2009). Suppression of amygdalar endocannabinoid signaling by stress contributes to activation of the hypothalamic-pituitaryadrenal axis. Neuropsychopharmacology 34, 2733-2745. doi: 10.1038/npp.20 09.114

Iyegbe, C., Campbell, D., Butler, A., Ajnakina, O., and Sham, P. (2014). The emerging molecular architecture of schizophrenia, polygenic risk scores and the clinical implications for GxE research. Soc. Psychiatry Psychiatr. Epidemiol. 49, 169-182. doi: 10.1007/s00127-014-0823-2

Jacobson, S. W., and Frye, K. F. (1991). Effect of maternal social support on attachment: experimental evidence. Child Dev. 62, 572-582.

Juhasz, G., Chase, D., Pegg, E., Downey, D., Toth, Z. G., Stones, K., et al. (2009). CNR1 gene is associated with high neuroticism and low agreeableness and interacts with recent negative life events to predict current depressive symptoms. Neuropsychopharmacology 34, 2019-2027. doi: 10.1038/npp.2009. 19

Kaplan, B. J., Giesbrecht, G. F., Leung, B. M. Y., Field, C. J., Dewey, D., Bell, R. C., et al. (2014). The alberta pregnancy outcomes and nutrition (APrON) cohort study: rationale and methods. Matern. Child Nutr. 10, 44-60. doi: 10.1111/j. 1740-8709.2012.00433.x

Keller, H. (2018). Universality claim of attachment theory: children's socioemotional development across cultures. Proc. Natl. Acad. Sci. U.S.A. 115, 11414-11419. doi: 10.1073/pnas.1720325115

Kelly, J. F., Zuckerman, T., and Rosenblatt, S. (2008). Promoting first relationships: a relationship-focused early intervention approach. Infants Young Children 21, 285-295. doi: 10.1097/01.IYC.0000336541.37379.0e

Kohlhoff, J., and Barnett, B. (2013). Parenting self-efficacy: links with maternal depression, infant behaviour and adult attachment. Early Hum. Dev. 89, 249256. doi: 10.1016/j.earlhumdev.2013.01.008

Kozlowska, K., and Elliott, B. (2014). "The school-aged assessment of attachment," in The Routledge Handbook of Attachment: Assessment, eds S. Farnfield and P. Holmes (London: Routledge), 102-118.

Lakatos, K., Nemoda, Z., Toth, I., Ronai, Z., Ney, K., Sasvari- Szekely, M., et al. (2002). Further evidence for the role of the dopamine D4 receptor (DRD4) gene in attachment disorganization: interaction of the exon III 48-bp repeat and the $-521 \mathrm{C} / \mathrm{T}$ promoter polymorphisms. Mol. Psychiatry 7:27. doi: 10.1038/sj.mp. 4000986

Lakatos, K., Toth, I., Nemoda, Z., Ney, K., Sasvari-Szekely, M., and Gervai, J. (2000). Dopamine D4 receptor (DRD4) gene polymorphism is associated with attachment disorganization in infants. Mol. Psychiatry 5:633. doi: 10.1038/sj. mp.4000773
Leadbeater, B. J., Bishop, S. J., and Raver, C. C. (1996). Quality of mothertoddler interactions, maternal depressive symptoms, and behavior problems in preschoolers of adolescent mothers. Dev. Psychol. 32, 280-288. doi: 10.1037/ 0012-1649.32.2.280

Leerkes, E. M. (2011). Maternal sensitivity during distressing tasks: a unique predictor of attachment security. Infant Behav. Dev. 34, 443-446. doi: 10.1016/ j.infbeh.2011.04.006

Letourneau, N. L., de Koning, A. P. J., Sekhon, B., Ntanda, H. N., Kobor, M., Deane, A. J., et al. (2019). Parenting interacts with plasticity genes in predicting behavioral outcomes in preschoolers. Can. J. Nurs. Res. 52, 290-307. doi: 10. $1177 / 0844562119863612$

Letourneau, N. L., Kozyrskyj, A. L., Cosic, N., Ntanda, H. N., Anis, L., Hart, M. J., et al. (2017). Maternal sensitivity and social support protect against childhood atopic dermatitis. Allergy Asthma Clin. Immunol. 13:26. doi: 10.1186/s13223017-0199-4

Leventhal, A., Jacobsen, T., Miller, L., and Quintana, E. (2004). Caregiving attitudes and at-risk maternal behavior among mothers with major mental illness. Psychiatr. Serv, 55, 1431-1433. doi: 10.1176/appi.ps.55.12.1431

Lewis-Morrarty, E., Degnan, K. A., Chronis-Tuscano, A., Pine, D. S., Henderson, H. A., and Fox, N. A. (2015). Infant attachment security and early childhood behavioral inhibition interact to predict adolescent social anxiety symptoms. Child Dev. 86, 598-613. doi: 10.1111/cdev.12336

Luijk, M. P. C. M., Tharner, A., Bakermans-Kranenburg, M. J., van Ijzendoorn, M. H., Jaddoe, V. W., Hofman, A., et al. (2011). The association between parenting and attachment security is moderated by a polymorphism in the mineralocorticoid receptor gene: evidence for differential susceptibility. Biol. Psychol. 88, 37-40. doi: 10.1016/j.biopsycho.2011.06.005

Lupica, C. R., Riegel, A. C., and Hoffman, A. F. (2004). Marijuana and cannabinoid regulation of brain reward circuits. Br. J. Pharmacol. 143, 227-234.

Lyons-Ruth, K. (2015). Dissociation and the parent-infant dialogue: a longitudinal perspective from attachment research. Attachment 9, 253-276.

Madigan, S., Bakermans-Kranenburg, M. J., Van Ijzendoorn, M. H., Moran, G., Pederson, D. R., and Benoit, D. (2006). Unresolved states of mind, anomalous parental behavior, and disorganized attachment: a review and metaanalysis of a transmission gap. Attach. Hum. Dev. 8, 89-111. doi: 10.1080/ 14616730600774458

Main, M., and Solomon, J. (1986). "Discovery of an insecuredisorganized/disoriented attachment pattern: procedures, findings and implications for the classification of bahavior," in Affective Development in Infancy, eds T. Brazelton and M. Youngman (New York, NY: Ablex), $111-123$.

Main, M., and Solomon, J. (1990). "Procedures for identifying infants as disorganized/disoriented during the Ainsworth strange situation," in Attachment in the Preschool Years, eds M. Greenberg, D. Cicchetti, and E. M. Cummings (Chicago, IL: University of Chicago Press), 121-160.

Main, M., and Stadtman, J. (1981). Infant response to rejection of physical contact by the mother: aggression, avoidance, and conflict. J. Am. Acad. Child Psychiatry 20, 292-307. doi: 10.1016/s0002-7138(09)60990-0

Matthey, S., Henshaw, C., Elliott, S., and Barnett, B. (2006). Variability in use of cut-off scores and formats on the Edinburgh Postnatal Depression Scale: implications for clinical and research practice. Arch. Womens Ment. Health 9 , 309-315. doi: 10.1007/s00737-006-0152-x

McGrath, J. J., Mortensen, P. B., Visscher, P. M., and Wray, N. R. (2013). Where GWAS and epidemiology meet: opportunities for the simultaneous study of genetic and environmental risk factors in schizophrenia. Schizophrenia Bull. 39, 955-959. doi: 10.1093/schbul/sbt108

McGraw, L. A., and Young, L. J. (2010). The prairie vole: an emerging model organism for understanding the social brain. Trends Neurosci. 33, 103-109. doi: 10.1016/j.tins.2009.11.006

Morecraft, R. J., and Yeterian, E. H. (2002). "Prefrontal cortex," in Encyclopedia of the Human Brain, ed. V. S. Ramachandran (Cambridge, MA: Academic Press), 11-26.

Newman, L., Sivaratnam, C., and Komiti, A. (2015). Attachment and early brain development - neuroprotective interventions in infant-caregiver therapy. Transl. Dev. Psychiatry 3:28647. doi: 10.3402/tdp.v3.28647

Obradović, J., Bush, N. R., Stamperdahl, J., Adler, N. E., and Boyce, W. T. (2010). Biological sensitivity to context: the interactive effects of stress reactivity and 
family adversity on socioemotional behavior and school readiness. Child Dev. 81, 270-289. doi: 10.1111/j.1467-8624.2009.01394.x

Okuyama, T., Kitamura, T., Roy, D. S., Itohara, S., and Tonegawa, S. (2016). Ventral CA1 neurons store social memory. Science 353, 1536-1541. doi: 10. 1126/science.aaf7003

Okuyama, T., Yokoi, S., Abe, H., Isoe, Y., Suehiro, Y., Imada, H., et al. (2014). A neural mechanism underlying mating preferences for familiar individuals in medaka fish. Science 343, 91-94. doi: 10.1126/science.1244724

Pappa, I., Szekely, E., Mileva-Seitz, V. R., Luijk, M. P., Bakermans-Kranenburg, M. J., van Ijzendoorn, M. H., et al. (2015). Beyond the usual suspects: a multidimensional genetic exploration of infant attachment disorganization and security. Attach. Hum. Dev. 17, 288-301. doi: 10.1080/14616734.2015.1037316

Patterson, N., Price, A. L., and Reich, D. (2006). Population structure and eigenanalysis. PLoS Genet. 2:e190. doi: 10.1371/journal.pgen.0020190

Pauli, W. M., O'Reilly, R. C., Yarkoni, T., and Wager, T. D. (2016). Regional specialization within the human striatum for diverse psychological functions. Proc. Natl. Acad. Sci. U.S.A. 113, 1907-1912. doi: 10.1073/pnas.1507610113

Plomin, R. (2013). Commentary: missing heritability, polygenic scores, and geneenvironment correlation. J. Child Psychol. Psychiatry 54, 1147-1149. doi: 10. $1111 /$ jcpp. 12128

Pop, V. J., Komproe, I. H., and van Son, M. J. (1992). Characteristics of the Edinburgh post natal depression scale in The Netherlands. J. Affect. Disord. 26, 105-110. doi: 10.1016/0165-0327(92)90041-4

Portella, A. K., Papantoni, A., Paquet, C., Moore, S., Rosch, K. S., Mostofsky, S., et al. (2020). Predicted DRD4 prefrontal gene expression moderates snack intake and stress perception in response to the environment in adolescents. PLoS One 15:e0234601. doi: 10.1371/journal.pone.0234601

Puig, J., Englund, M., Simpson, J., and Collins, W. (2013). Predicting adult physical illness from infant attachment: a prospective longitudinal study. Health Psychol. 32, 409-417. doi: 10.1037/a0028889

Ranganathan, M., and D'Souza, D. C. (2006). The acute effects of cannabinoids on memory in humans: a review. Psychopharmacology 188, 425-444. doi: 10.1007/ s00213-006-0508-y

Rini, C., Schetter, C. D., Hobel, C. J., Glynn, L. M., and Sandman, C. A. (2006). Effective social support: antecedents and consequences of partner support during pregnancy. Pers. Relationsh. 13, 207-229. doi: 10.1111/j.1475-6811.2006. 00114.x

Robinson, J. L., Laird, A. R., Glahn, D. C., Blangero, J., Sanghera, M. K., Pessoa, L., et al. (2012). The functional connectivity of the human caudate: an application of meta-analytic connectivity modeling with behavioral filtering. NeuroImage 60, 117-129. doi: 10.1016/j.neuroimage.2011.12.010

Roisman, G. I., Newman, D. A., Fraley, R. C., Haltigan, J. D., Groh, A. M., and Haydon, K. C. (2012). Distinguishing differential susceptibility from diathesisstress: recommendations for evaluating interaction effects. Dev. Psychopathol. 24, 389-409. doi: 10.1017/s0954579412000065

Romero-Fernandez, W., Borroto-Escuela, D. O., Agnati, L. F., and Fuxe, K. (2013). Evidence for the existence of dopamine D2-oxytocin receptor heteromers in the ventral and dorsal striatum with facilitatory receptor-receptor interactions. Mol. Psychiatry 18, 849-850. doi: 10.1038/mp.2012.103

Rutherford, H. J. V., Maupin, A. N., Landi, N., Potenza, M. N., and Mayes, L. C. (2017). Parental reflective functioning and the neural correlates of processing infant affective cues. Soc. Neurosci. 12, 519-529. doi: 10.1080/17470919.2016. 1193559

Schore, A. N. (2000). Attachment and the regulation of the right brain. Attach. Hum. Dev. 2, 23-47. doi: 10.1080/146167300361309

Schore, A. N. (2001). Effects of a secure attachment relationship on right brain development, affect regulation, and infant mental health. Infant Ment. Health J. 22, 7-66.

Schultz, W. (2000). Multiple reward signals in the brain. Nat. Rev. Neurosci. 1, 199-207. doi: $10.1038 / 35044563$

Shannon, P. (2003). Cytoscape: a software environment for integrated models of biomolecular interaction networks. Genome Res. 13, 2498-2504. doi: 10.1101/ gr.1239303

Silveira, P. P., Pokhvisneva, I., Parent, C., Cai, S., Rema, A. S. S., Broekman, B. F. P., et al. (2017). Cumulative prenatal exposure to adversity reveals associations with a broad range of neurodevelopmental outcomes that are moderated by a novel, biologically informed polygenetic score based on the serotonin transporter solute carrier family C6, member 4. Dev. Psychopathol. 29, 1601-1617. doi: 10.1017/s0954579417001262
Simpson, J. A. (1999). "Attachment theory in modern evolutionary perspective," in Handbook of Attachment: Theory, Research, and Clinical Applications, eds J. Cassidy and P. R. Shaver (New York, NY: The Guilford Press), 115-140.

Skowron, E. A., Cipriano-Essel, E., Gatzke-Kopp, L. M., Teti, D. M., and Ammerman, R. T. (2014). Early adversity, RSA, and inhibitory control: evidence of children's neurobiological sensitivity to social context. Dev. Psychobiol. 56, 964-978. doi: 10.1002/dev.21175

Solomon, J., and George, C. (2016). "The measurement of attachment security and related constructs in infancy and early childhood," in Handbook of Attachment: Theory, Research, and Clinical Applications, 3rd Edn, eds J. Cassidy and P. R. Shaver (New York, NY: The Guilford Press), 366-396.

Sroufe, L. A. (2005). Attachment and development: a prospective, longitudinal study from birth to adulthood. Attach. Hum. Dev. 7, 349-367. doi: 10.1080/ 14616730500365928

Sroufe, L. A., Egeland, B., Carlson, E., and Collins, A. (2005). "Placing early experiences in developmental context," in Attachment from Infancy to Adulthood, eds K. E. Grossman, K. Grossman, and E. Waters (New York, NY: The Guilford Press), 48-70.

Stams, G. J. M., Juffer, F., and van Ijzendoorn, M. H. (2002). Maternal sensitivity, infant attachment, and temperament in early childhood predict adjustment in middle childhood: the case of adopted children and their biologically unrelated parents. Dev. Psychol. 38, 806-821. doi: 10.1037/0012-1649.38.5.806

Stapleton, J. A., Sutherland, G., O'Gara, C., Spirling, L. I., and Ball, D. (2011). Association between DRD2/ANKK1 Taq1A genotypes, depression and smoking cessation with nicotine replacement therapy. Pharmacogenet. Genomics 21, 447-453. doi: 10.1097/FPC.0b013e328347473a

Statistics Canada (2020). Education Highlight Tables 2016 Census Statistics Canada. Statistics Canada.

Tao, R., Li, C., Jaffe, A. E., Shin, J. H., Deep-Soboslay, A., Yamin, R., et al. (2020). Cannabinoid receptor CNR1 expression and DNA methylation in human prefrontal cortex, hippocampus and caudate in brain development and schizophrenia. Transl. Psychiatry 10:158. doi: 10.1038/s41398-020-0832-8

Teti, D., and Kim, B.-R. (2014). "Infants and preschool children: observational assessments of attachment, a review and discussion of clinical applications," in The Routledge Handbook of Attachment: Assessment, eds S. Farnfield and P. Holmes (Milton Park: Routledge), 102-118.

Thomas, J. C., Letourneau, N. L., Campbell, T. S., Tomfohr-Madsen, L., and Giesbrecht, G. F. (2017). Developmental origins of infant emotion regulation: mediation by temperamental negativity and moderation by maternal sensitivity. Dev. Psychol. 53, 611-628. doi: 10.1037/dev0000279

Thompson, R. A. (2016). "Early attachment and later development," in Handbook of Attachment: Theory, Research, and Clinical Applications, 3rd Edn, eds J. Cassidy and P. R. Shaver (New York, NY: The Guilford Press), 330-348.

Ulmer-Yaniv, A., Avitsur, R., Kanat-Maymon, Y., Schneiderman, I., ZagoorySharon, O., and Feldman, R. (2016). Affiliation, reward, and immune biomarkers coalesce to support social synchrony during periods of bond formation in humans. Brain Behav. Immun. 56, 130-139. doi: 10.1016/j.bbi. 2016.02.017

van Ijzendoorn, M. H., and Bakermans-Kranenburg, M. J. (2006). DRD4 7-repeat polymorphism moderates the association between maternal unresolved loss or trauma and infant disorganization. Attach. Hum. Dev. 8, 291-307. doi: 10.1080/ 14616730601048159

van IJzendoorn, M. H., and Kroonenberg, P. M. (1988). Cross-cultural patterns of attachment: a meta-analysis of the strange situation. Child Dev. 59, 147-156. doi: 10.1111/j.1467-8624.1988.tb03202.x

van Ijzendoorn, M. H., Schuengel, C., and Bakermans-Kranenburg, M. J. (1999). Disorganized attachment in early childhood: meta-analysis of precursors, concomitants, and sequelae. Dev. Psychopathol. 11, 225-250. doi: 10.1017/ S0954579499002035

Van Overwalle, F. (2009). Social cognition and the brain: a meta-analysis. Hum. Brain Mapp. 30, 829-858. doi: 10.1002/hbm.20547

Ward, M. J., and Carlson, E. A. (1995). Associations among adult attachment representations, maternal sensitivity, and infant-mother attachment in a sample of adolescent mothers. Child Dev. 66, 69-79. doi: 10.1111/j.1467-8624.1995. tb00856.x

Weinberg, M. K., Tronick, E. Z., Cohn, J. F., and Olson, K. L. (1999). Gender differences in emotional expressivity and self-regulation during early infancy. Dev. Psychol. 35, 175-188. doi: 10.1037/0012-1649.35.1.175 
Weiss, S. J., Wilson, P., Hertenstein, M. J., and Campos, R. (2000). The tactile context of a mother's caregiving: implications for attachment of low birth weight infants. Infant Behav. Dev. 23, 91-111. doi: 10.1016/S0163-6383(00)00030-8

Wille, D. E. (1991). Relation of preterm birth with quality of infant-mother attachment at one year. Infant Behav. Dev. 14, 227-240. doi: 10.1016/01636383(91)90007-F

Young, S. E., Smolen, A., Corley, R. P., Krauter, K. S., DeFries, J. C., Crowley, T. J., et al. (2002). Dopamine transporter polymorphism associated with externalizing behavior problems in children. Am. J. Med. Genet. 114, 144-149. doi: $10.1002 /$ ajmg. 10155

Zanettini, C., Panlilio, L. V., Alicki, M., Goldberg, S. R., Haller, J., and Yasar, S. (2011). Effects of endocannabinoid system modulation on cognitive and emotional behavior. Front. Behav. Neurosci. 5:57.

Zuurman, L., Ippel, A. E., Moin, E., and van Gerven, J. M. (2009). Biomarkers for the effects of cannabis and THC in healthy volunteers. Br. J. Clin. Pharmacol. 67, 5-21. doi: 10.1111/j.1365-2125.2008.03 329.x
Conflict of Interest: The authors declare that the research was conducted in the absence of any commercial or financial relationships that could be construed as a potential conflict of interest.

Publisher's Note: All claims expressed in this article are solely those of the authors and do not necessarily represent those of their affiliated organizations, or those of the publisher, the editors and the reviewers. Any product that may be evaluated in this article, or claim that may be made by its manufacturer, is not guaranteed or endorsed by the publisher.

Copyright (c) 2021 Potter-Dickey, Letourneau, Silveira, Ntanda, Giesbrecht, Hart, Dewell and de Koning. This is an open-access article distributed under the terms of the Creative Commons Attribution License (CC BY). The use, distribution or reproduction in other forums is permitted, provided the original author(s) and the copyright owner(s) are credited and that the original publication in this journal is cited, in accordance with accepted academic practice. No use, distribution or reproduction is permitted which does not comply with these terms. 